\title{
ELITES LOCALES, GESTIÓN PÚBLICA Y MERCADO PREINDUSTRIAL: LA ADMINISTRACIÓN DE LOS PÓSITOS EN ARAGÓN DURANTE LA EDAD MODERNA*
}

\author{
Jose ANTONIO MATEOS RoYO \\ Universidad de Zaragoza
}

En la actualidad, los estudios sobre la política de abastos municipal practicada en España durante las Edades Media y Moderna atraviesan una fase de claro estancamiento. Desarrollados con fuerza durante los años setenta y ochenta del siglo XX, con frecuencia ligados a estudios de Historia Urbana, tanto el menor interés prestado a las investigaciones económicas dentro de la Historia Medieval y Moderna en beneficio de análisis políticos, sociales y culturales como la concentración de los economistas en la Época Contemporánea han generado un particular abandono de la imbricación existente entre la evolución de la gestión pública y los mercados locales en las etapas precedentes ${ }^{1}$. Al constituir una línea de investigación decisiva para ponderar los cambios del mercado preindustrial, su abandono ha impedido rellenar lagunas y ampliar perspectivas de trabajo para ofrecer una visión más plena de los problemas vinculados a esta temática.

Como ha procedido la restante Historiografía europea ${ }^{2}$, las investigaciones sobre el tema se han centrado en España en las principales ciudades -sobre todo en Madrid²

\footnotetext{
* Este trabajo se incluye en el proyecto HUM2004-00537, titulado «Absolutismo y mercado. La política del Estado, siglos XVII-XVIII» y financiado por el Ministerio de Ciencia y Tecnología.

1. AlBEROLA, Armando, «Aproximación a la reciente historiografía española», Jerónimo Zurita, 71, (1997), pp. 7-18 y FERNÁNDEZ CLEMENTE, Eloy, «La historia económica de España en los últimos veinte años (1975-1995). Crónica de una escisión anunciada», Jerónimo Zurita, 71, (1997), pp. 59-94.

2. Para el área mediterránea, destacan los estudios sobre el abasto de París y Roma en la Edad Moderna de Meuvret, Jean, Etudes d'Histoire économique, Paris, 1971; KaPlan, Steven L. Les ventres de Paris. Pouvoir et approvisionnement dans la France d'Ancien Régime, Paris, 1988 y MARTINAT, Monica, «Le marché des céréales à Rome au XVII siècle», Histoire and Mesure, X-3/4, (1995), pp. 313-338.

3. BENNASSAR, Bartolomé, Valladolid en el siglo de Oro. Una ciudad de Castilla y su entorno agrario en el siglo XVI, Valladolid, 1989; CHACóN, Francisco, Murcia en la centuria del Quinientos, Murcia, 1979; Cremades, Carmen María, Alimentación y consumo en la ciudad de Murcia durante el siglo
} 
con un claro predominio de los núcleos portuarios sobre los enclaves del interior. Con todo, la evidente marginación de núcleos modestos de carácter más agrario ha impedido contrastar sus objetivos y desempeños con los de los grandes centros urbanos. Como ilustra a la perfección el trabajo de $\mathrm{Castro}^{4}$, idéntica descompensación entraña el tratamiento privilegiado concedido a ciertos períodos históricos (reinados de los Reyes Católicos, Felipe II, Fernando VI y Carlos III), donde una documentación abundante o accesible indicaba una clara expansión del control público sobre el mercado de grano. Más difícil de precisar, el reajuste de esta intervención pública durante el siglo XVII ha sido orillado pese a sus evidentes consecuencias económicas y sociales en el proceso de transformación de un sistema feudal a otro de signo capitalista. Obstáculo añadido, la insuficiente vinculación de los procesos económicos analizados con los cambios políticos, sociales y culturales que tenían lugar en el ámbito local durante este amplio período ha restado con mucha frecuencia profundidad y nitidez a las investigaciones realizadas.

Desfavorecida por el escaso tratamiento de la hacienda municipal durante la Edad Moderna dentro de la Historiografía española ${ }^{5}$, ante esta aproximación fragmentada, la gestión municipal de los pósitos durante el Antiguo Régimen y su incidencia sobre el mercado de grano ha carecido de valoraciones precisas. Al tiempo, no se han ponderado lo suficiente los cambiantes intereses de las elites locales que controlaban los concejos ni el desarrollo de procesos de consenso y conflicto en torno al mercado público de grano con otras instituciones y grupos sociales que condicionaban la eficacia del control público. Estas deficiencias han consolidado una visión estática de la intervención municipal y el mercado preindustrial que ocluye sus serias transformaciones sociales y económicas en la Edad Moderna, así como sus nexos con las acaecidas en la Época Contemporánea.

XVIII (1701-1766), Murcia, 1984; MARCOS MARTIN, Alberto, Economía, sociedad y pobreza en Castilla: Palencia, 1500-1814, Palencia, 1985 (2 vols); Ringrose, David R. Madrid y la economía española, 1560-1850, Madrid, 1980; CASTRO, Concepción de, El pan de Madrid. El abasto de las ciudades españolas del Antiguo Régimen, Madrid,1987; GutiÉRrez Alonso, Adriano, Estudio sobre la decadencia de Castilla. La ciudad de Valladolid en el siglo XVII, Valladolid, 1989; BERNABÉ, David, Hacienda y mercado urbano en la Orihuela foral moderna, Alicante, 1989; MARTínEZ RUIZ, José Ignacio, Finanzas municipales y crédito público en la España Moderna. La hacienda de la ciudad de Sevilla, 1528-1768, Sevilla, 1992 y «El mercado internacional de cereales y harina y el abastecimiento de la periferia española en el siglo XVIII: Cádiz, entre la regulación y el mercado», Investigaciones de Historia Económica, 1, (2005), pp. 45-79; AGÜERO, María Teresa, «Evolución del pósito alicantino durante el reinado de Carlos III (1759-1788)»: los conflictos en torno al pan», Revista de Historia Moderna, 16, (1997), pp. 331-352; SolA, Carlos, Abasto de pan y política alimentaria en Pamplona (siglos XVI-XX), Pamplona, 2001 y BERnARDOS, José Ubaldo, Trigo castellano y abasto madrileño. Los arrieros y comerciantes segovianos en la Edad Moderna, Salamanca, 2003.

4. CAStro, Concepción de, El pan..., pp. 47-113.

5. PASSOLA, Antonio, La historiografia sobre el municipio en la España Moderna, Lleida, 1997, pp. 139152 y GutiÉRrez Alonso, A. «Ciudades y monarquía. Las finanzas de los municipios castellanos en los siglos XVI y XVII», en RiBot, Luis y DE RosA, Luigi. (eds.), Ciudad y mundo urbano en la Época Moderna, Madrid, 1997, pp. 187-211. 
El presente artículo aborda estos problemas al analizar el control municipal sobre el mercado de grano ejercido en Aragón a través de los pósitos durante la Edad Moderna. Amén de permitir una visión integrada de relaciones políticas y sociales junto a procesos económicos para la época preindustrial, la elección del tema incorpora otros motivos. Vincula la evolución de la hacienda municipal y del control público sobre el mercado para establecer sus características, causas y repercusiones económicas y sociales. Sin descuidar la intervención municipal en el abasto urbano, abarca núcleos agrarios de modesto tamaño y expone sus razones económicas y el grado de apoyo social. Junto al estudio de los intereses de las elites locales en el mercado frente a los de otros grupos sociales, considera la creciente intervención estatal sobre la gestión municipal y el funcionamiento de los mercados locales. El amplio espectro temporal abarcado permite relacionar la reforma de la gestión municipal con notables transformaciones económicas, políticas, sociales y culturales que afectan a la composición y estrategia de las elites locales, las relaciones vigentes entre estratos y su distinto acceso al mercado. La perspectiva regional adoptada facilita la comprensión de la compleja relación de estas variables para indicar soluciones o perspectivas de trabajo que puedan adaptarse al análisis de otros territorios.

\section{EL SIGLO XVI}

De forma fehaciente, Aragón conoció durante el siglo XVI un auge económico y demográfico que introdujo cambios sustanciales en la producción y comercialización agraria. En primer lugar, tuvo lugar una fuerte expansión demográfica y urbana ${ }^{6}$, fruto no sólo del crecimiento natural sino de la presencia de fuertes flujos migratorios procedentes del Suroeste de Francia desde mediados del siglo XVI hasta alcanzar su cenit entre 1580 y 1635. En segundo término, distintos factores económicos promovieron los intercambios comerciales: la mejora de las comunicaciones, la consolidación de una burguesía nativa mercantil ${ }^{7}$, el desarrollo de los mercados y las ferias (destacan las celebradas en Huesca, Barbastro, Daroca y Sariñena ${ }^{8}$ ) así como la mayor estabilidad monetaria tras adoptarse en 1519 y 1528 la ley y peso de Castilla en las piezas de plata y oro acuñadas en Aragón, ${ }^{9}$ que facilitó el uso de las monedas castellanas en las transacciones. En respuesta a la creciente demanda de alimentos, no sólo se generaron nuevas roturaciones en búsqueda de un crecimiento extensivo de la producción, sino se aumentaron y mejoraron los sistemas de regadío en un claro afán por incrementar la

\footnotetext{
6. SALAS, José Antonio, «La inmigración francesa en Aragón en la Edad Moderna», Estudios, 85-86, (1985), pp. 51-77 y «La evolución demográfica aragonesa en los siglos XVI y XVII», en NADAL, Jordi, (ed.), $L a$ evolución demográfica bajo los Austrias, Alicante, 1991, pp. 169-179.

7. GómeZ ZorRaQUINO, José Ignacio, La burguesía mercantil en el Aragón de los siglos XVI y XVII, Zaragoza, 1987.

8. SAN VICENTE, Ángel, Instrumentos para una historia social y económica del trabajo en Zaragoza durante los siglos XV al XVIII, Zaragoza, 1988, vol.I, pp. 306, 391-392.

9. Beltrán, Pío, Obras Completas, Zaragoza, 1972, vol. II, pp. 448-456 y MATEU, F. «El sistema monetario en Aragón. Síntesis histórica», en La moneda aragonesa, Zaragoza, 1983, pp. 113-115.
} 
productividad $^{10}$. Como resultado de estas iniciativas, la producción de cereal creció de forma general en Aragón, la vid en muchas poblaciones y el olivar en zonas de especial aptitud climática ${ }^{11}$. Como demuestra el fuerte crecimiento de las reses vinculadas a la Casa de Ganaderos de Zaragoza ${ }^{12}$, estimado en un 80\% entre 1516 y 1599, la citada demanda de productos agrarios estimuló asimismo los usos pecuarios para incrementar la cabaña ganadera existente en el reino.

Región productora y exportadora de cereal, la política de abastos aplicada por las autoridades públicas aragonesas en este siglo de crecimiento guarda fuertes semejanzas con la meseta de Castilla por su condición de territorio interior. Beneficiadas en su suministro por el transporte marítimo, que abarata mucho los costes frente al terrestre, las poblaciones costeras no pretendían un férreo control del mercado público de grano y se decantaban por la concesión de exenciones y créditos gratuitos a los tratantes para favorecer una importación de trigo ya potenciada por la fuerte demanda de la población. A este planteamiento respondían las principales ciudades costeras ${ }^{13}$ sitas en la Corona de Aragón -Barcelona, Valencia, Alicante- al constituir el mar Mediterráneo desde la Antigüedad un activo mercado de grano ${ }^{14}$. Por el contrario, la dificultad de las comunicaciones agravaba en el interior el impacto de las malas cosechas y producía alzas de precios mayores que en la costa. Esta situación promovió la utilización de métodos de control más directos, como la «tasa general» castellana ${ }^{15}$ o las vedas de exportar trigo de Aragón dispuestas desde la Edad Media por la Diputación del precio al rebasar éste un precio límite en el Almudí o mercado público de granos de Zaragoza ${ }^{16}$.

La política de abastos municipal en el Aragón del Quinientos halló un claro eje en la creación de pósitos, denominados por lo común cámara del trigo, administración del trigo o de las panaderías. La cronología de su creación resulta imprecisa en ciertos

10. COLAS, Gregorio, «Las transformaciones de la superficie agraria aragonesa en el siglo XVI: los regadíos. Aproximación a su estudio», en Congreso de historia rural (siglos XV-XIX), Madrid, 1984, pp. 523534.

11. LATORRE, José Manuel, «La producción agraria en el obispado de Huesca (siglos XVI-XVII)», Jerónimo Zurita, 59-60, (1991), pp. 131-132, 145; PEIRÓ, Antonio, Especialización olivarera y crecimiento económico. Caspe en el siglo XVIII, Caspe, 2000, pp. 14-26 y MATEOS José Antonio, Auge y decadencia de un municipio aragonés: el concejo de Daroca en los siglos XVI y XVII, Daroca, 1997, pp. 342.

12. GRACIA, Daniel, La ganadería zaragozana durante el siglo XVI: la cofradía de San Simón o San Judas o Casa de Ganaderos de Zaragoza, Zaragoza, 1998, (memoria de licenciatura inédita).

13. GIRALT, Enric, «En torno al precio del trigo en Barcelona en el siglo XVI», Hispania, 70, (1958), pp. 38-58; PALOP, José Miguel, Hambre y lucha antifeudal. Las crisis de subsistencias en Valencia (siglo XVIII), Madrid, 1977, pp. 5-35; GIMÉNEZ, Enrique Alicante en el siglo XVIII. Economía de una ciudad portuaria en el Antiguo Régimen, Valencia, 1981, pp. 299-306; FERRERO, Remedios, «Impuestos municipales sobre los cereales en la Valencia del Quinientos», Estudis, 12, (1986), pp. 55-70 y AGÜERO, María Teresa, «Evolución...». Este diseño del suministro de grano es seguido por las grandes ciudades portuarias castellanas volcadas al Atlántico como Cádiz y Sevilla según MARTíNEZ RUIZ, José Ignacio, Finanzas..., pp. 178-180 y «El mercado internacional...».

14. Marin, Brigitte y Virlouvet, Catherine (dirs), Nourrir les cités de Méditerranée, Paris, 2003.

15. CAStro, Concepción de, El pan..., pp. 69-85.

16. ColAS, Gregorio y SALAS, José Antonio, Aragón en el siglo XVI, Zaragoza, 1982, pp. 26. 
núcleos por las dificultades de las administraciones iniciales con un funcionamiento de carácter temporal para consolidarse; pero el mejor acceso a un abasto regular de grano gracias a su capacidad financiera y coercitiva o a la abundante producción del entorno resulta un factor decisivo en este proceso ${ }^{17}$. La fundación de pósitos afectó desde fines del siglo XV y principios del siglo XVI no sólo a ciudades -Daroca, Zaragoza-, sino a núcleos modestos e insertos en el medio rural como la villa de Puertomingalvo. Condición necesaria para permitir una intervención estable en el mercado por parte de los pósitos, el suministro obligado de las panaderías en los silos municipales se afirmó en las principales ciudades y bastantes villas ya a mediados del siglo XVI. La creciente demanda de cereal debida a la expansión demográfica movió a las ciudades más modestas -Jaca, Albarracín- a crear pósitos por estas fechas. Como demuestran los pósitos gestados en el Bajo Aragón y valle del Matarraña, muchas villas y lugares siguieron su ejemplo hasta fines del siglo XVI.

A la hora de ponderar las razones de su implantación, los pósitos recogen un interés por la protección al consumidor latente en los principios de política económica de la Edad Media ${ }^{18}$ : algunos surgen o se consolidan tras padecerse serias carestías de grano que legitiman su instauración. Estuvieran o no integradas en los concejos, las elites rectoras añaden su interés como productores o distribuidores de grano por expandir el mercado público local de cereal y sustentar la demanda interna, proceso de especial dificultad en las economías preindustriales ${ }^{19}$. Así se explica la extensión de los pósitos a núcleos agrarios en zonas cerealistas, con menor necesidad de un abasto regular de trigo que las grandes ciudades. Al desarrollar mecanismos de contención frente a la inflación de precios típica de la centuria, que incidía con especial fuerza en los productos agrarios, se favorecía el consumo de grano y se potenciaba la capacidad adquisitiva de la población. A cambio de ver rebajado el precio de mercado, el productor se veía

17. SAN ViCEnTE, Ángel, Colección de Fuentes de Derecho municipal del Bajo Renacimiento, Zaragoza, 1970, pp. 292-293, 299, 307, 403, 534, 543-545, 608; SALAS, José Antonio, La población de Barbastro en los siglos XVI y XVII, Zaragoza, 1981, pp. 99; LÓPEZ CORREAS, Pedro J. La villa de Epila en el siglo XVI: vida y costumbres, Épila, 1991, pp. 70-72, GÓMEZ DE VALENZUELA, Manuel, Documentos del valle de Tena (siglo XVI), Zaragoza, 1992, pp. 61-63, 259-66; PEIRÓ, Antonio, «Feudalismo, organización campesina y pósitos en Aragón» en VII Congreso de Historia Agraria, 1993, (trabajo mimeografiado); UrZAY, José Ángel, SANGÜESA, Antonio e IBARRA, Isabel, Calatayud a finales del siglo XVI y principios del XVII (1570-1610). La configuración de una sociedad barroca. Calatayud, 2001, pp. 137-141; LATORRE, José Manuel (coord.), Estudios históricos sobre la Comunidad de Albarracín, Tramacastilla, 2003, vol.I, pp. 187 y vol II, pp. 242, 277; MEDRANO, Javier, Puertomingalvo en el siglo XV, Teruel, 2006, pp. 272-275 y MATEOS José Antonio, Auge..., pp. 279-284, «Municipio y mercado en el Aragón moderno: el abasto de trigo en Zaragoza (siglos XVI y XVII)», Espacio, Tiempo y Forma, IV, 15, (2002), pp. 37-39 y «Municipio y mercado en el Aragón moderno: la Cámara del Trigo de Albarracín (16501710)», Teruel, 90/ 2, (2003-2005), pp. 63 y «Economía y poder local en el valle del Matarraña (siglos XVI y XVII)», en Historia de la Comarca del Matarraña. Edad Moderna, (en prensa).

18. Postan, M.M y HabakkuK, H.J. (eds.), Historia económica de Europa, Madrid, 1967, vol.III, pp. 507-547.

19. VRIES, Jean de, La economía de Europa en un periodo de crisis, 1600-1750, Madrid, 1987, pp. 181185 . 
compensado por la mayor regularidad de la demanda de grano. Se conseguía así incentivar el cultivo de cereal al procurarse una integración voluntaria del campesino en el mercado ${ }^{20}$. Bien por problemas económicos o disensiones políticas y sociales, este sistema no se consolidó por igual en todas las poblaciones. Cuanto más abundante y regular era el abasto del pósito, generaba mayor confianza y dinamismo en un mercado en expansión. Al constituir un artículo indispensable, los efectos de esta intervención excedían los límites del comercio local o comarcal de grano y afectaban al conjunto de la economía aragonesa.

Esta fuerte eclosión de pósitos se vincula con otras iniciativas municipales ${ }^{21}$ que ganaron fuerza a partir de mediados del siglo XVI como un mayor control de la molienda mediante la construcción o adquisición de molinos o la promoción de los intercambios de cereal al intentar homogeneizar las medidas para áridos locales con las de Zaragoza, patrón oficial aragonés, según lo dispuesto en las Cortes de Monzón de 1533. Todos estos esfuerzos por sustentar el mercado interno de cereal se beneficiaron de un claro consenso social al confluir los intereses de grupos productores y consumidores de grano así como de sectores perceptores de rentas gracias a la expansión económica y el auge municipal vividos por Aragón durante el siglo $\mathrm{XVI}^{22}$. Un ejemplo equivalente de intervención pública local en la actividad económica viene dado por el incremento y mejora de los regadíos, que potenció los rendimientos de propietarios y tenentes a la vez que aumentó la detracción de señores laicos o eclesiásticos y comerciantes, principales arrendatarios de estas rentas ${ }^{23}$. La financiación del gasto municipal dedicado a estos objetivos mediante la contratación de censales, en provecho de la minoría rentista ciudadana, limitó la presión fiscal sobre la población local y favoreció su aceptación de esta política ${ }^{24}$.

Esta interpretación se aviene bien con la composición social de la elite municipal durante los siglos XVI y XVII ${ }^{25}$, integrada en las principales ciudades por ciudadanos

20. AYMARD, Maurice, «Autoconsommation et marchés: Chayanov, Labrousse ou Le Roy Ladurie ?», Annales, Economies, Societés, Civilisations, 38/6, (1983), pp. 1392-410.

21. Salas, José Antonio, La población..., pp. 105-106, MATEOS, José Antonio, Auge..., pp. 267-273 y «Economía...».

22. Este proceso no excluye el estallido de tensiones políticas y sociales en Aragón durante el siglo XVI, tal y como se demuestra en ColAs, Gregorio, y SALAS, José Antonio, Aragón....

23. COLAS, Gregorio, «Las transformaciones...» y MATEOS, José Antonio, «The making of a new landscape: town councils and water in the kingdom of Aragon during the sixteenth century», Rural History, 9, 2, (1998), pp. 123-139.

24. SALAS, José Antonio «Las haciendas concejiles aragonesas en los siglos XVI y XVII. De la euforia a la quiebra», en Poder politico e instituciones en la España Moderna, Alicante, 1992, pp. 31-38 y MATEOS, José Antonio, «Propios, arbitrios y comunales: la hacienda municipal en el reino de Aragón durante los siglos XVI y XVII», Revista de Historia Económica, XXI, 1, (2003), pp. 63-66.

25. Como mejores síntesis, GómeZ ZorRAQUINO, José Ignacio, «Ni señores, ni campesinos/artesanos. El gobierno de los ciudadanos en Aragón», en ARANDA, Francisco José (coord.), Burgueses o ciudadanos en la España Moderna, Cuenca, 2003, pp. 357-395 y «Del concejo foral al ayuntamiento borbónico. La mudanza en el poder municipal (siglos XVI-XVII)» en El municipio en Aragón. 25 siglos de Historia, 
dedicados al comercio y las profesiones liberales a la vez que propietarios de tierras. Su control político se vio sancionado a mediados del siglo XV al introducir la monarquía en la Corona de Aragón la insaculación para elegir los cargos municipales importantes ${ }^{26}$. Con la excepción de Zaragoza, controlada en exclusiva por los ciudadanos, éstos compartieron el poder político local en las ciudades con un estrato de infanzones que consolidó su status económico y social al ejercer el comercio y la judicatura desde el siglo $\mathrm{XV}^{27}$. Con menor poder decisorio, artesanos y labradores ocupaban cargos menores ligados a tareas de supervisión del mercado, arriendo de propios o control de comunales. La prohibición de ejercer oficios mecánicos y la obligación de garantizar bienes cada vez mayores para desempeñar los principales puestos municipales restringían el acceso de estos sectores. Tolerada una presencia limitada a sus estratos más pudientes, esta representación fue rebajada en el siglo XVII. En villas y lugares de menor peso demográfico y económico, hidalgos e infanzones y labradores o artesanos acomodados componían la minoría rectora, grupos que se solían repartir mitad por mitad los principales $\operatorname{cargos}^{28}$. En núcleos bajo dominio laico o eclesiástico, su composición vino influida por el derecho señorial a designar ciertos oficiales, a menudo entre candidatos propuestos por el concejo.

Esta confluencia de intereses entre la elite y la mayoría de la población en torno al mercado de grano ${ }^{29}$ se hizo explícita durante el siglo XVI al generar la creación del

Zaragoza, 2004, pp. 99-135. Como estudios concretos de las elites municipales, SALAS, José Antonio, La población..., pp. 275-84, 296-304; JARQUE, Encarna, «La oligarquía urbana de Zaragoza en los siglos XVI y XVII. Estudio comparativo con Barcelona», Jerónimo Zurita, 69-70, (1994), pp. 147-167; MATEOS, José Antonio, Auge..., pp. 81-102; UrZAY, José Ángel, SANGÜESA, Antonio, e IBARRA, Isabel, Calatayud..., pp. 87-109 y GómEZ ZorRAQUINO, José Ignacio, «La ciudad de Huesca y su gobierno municipal. Aportación al estudio de las elites urbanas en el siglo XVI», en Actas del XVII Congreso de Historia de la Corona de Aragón, Barcelona, 2003, vol.III, pp. 365-373.

26. Sobre la implantación del método insaculatorio en Aragón, FALCóN, María Isabel, «Origen y desarrollo del municipio medieval en el reino de Aragón», Estudis Balearics, 31, (1988), pp. 73-91.Su rápida difusión por la Corona de Aragón derivó de su aceptación por las elites para regular el acceso al poder local y relegar las luchas de bandos que alteraban el orden y permitían la intervención nobiliaria desde la Baja Edad Media, como las descritas para el reino aragonés en SARASA, Esteban, Sociedad y conflictos sociales en Aragón, siglos XIII-XV, Madrid, 1981. El grado de intervención en el nombramiento de cargos municipales que permitía la insaculación al monarca en la Corona ha generado una seria controversia, recogida en JARQUE, E. y SALAS, José Antonio, «El poder municipal aragonés en tiempos de Felipe II» en Martínez Ruiz, Enrique (ed.), Madrid, Felipe II y las ciudades de la Monarquía, Madrid, 2000, tomo I, pp. 199-215.

27. Así se evidencia en Salas, José Antonio, La población..., pp. 276-281; MATEOS, José Antonio, Auge..., pp. 94; URZAY, José Ángel, SANGÜESA, Antonio, e IBARRA, Isabel, Calatayud...p. 88; GómEZ ZORRAQUINO, José Ignacio «La ciudad...», pp. 373-380, «Ni señores...», pp. 367-370 y «Del concejo foral...», pp. 119-127; LATORRE, José Manuel, Estudios..., vol. II, pp. 288, 296, 335, 368-369.

28. Como ejemplos, véase SAN VICENTE, Ángel, Colección...pp. 85-89, 133-138, 188-191, 280-285, 478485 y Gómez De VALEnZuela, Manuel, Documentos... pp. 218-224.

29. Este consenso refleja los intereses comunes entre grupos sociales y sus expectativas de progreso al cerrarse acuerdo descritos por GAUTHIER, David, La moral por acuerdo, Barcelona, 1994 y POLANYI, Karl, La gran transformación. Los orígenes políticos y económicos de nuestro tiempo, México, 1992. 
pósito un claro reparto de los administradores entre los estratos sociales implicados, a semejanza de lo que ocurría en los organismos destinados a proveer a los núcleos habitados de un suministro regular de agua potable ${ }^{30}$. Elegido por insaculación y bajo la supervisión de jurados y contables, el cambrero o gestor del pósito se vinculó en las principales ciudades -Zaragoza, Huesca, Barbastro, Calatayud- a ciudadanos e infanzones, con predominio de los mercaderes ${ }^{31}$. Su designación en núcleos con un mayor carácter agrario y sentimiento comunal la gestión del pósito se hallaba más repartida ${ }^{32}$. En la villa de señorío de Alcañiz rigió en la segunda mitad del siglo XVI un sistema mixto: la compra de grano era confiada a un cambrero elegido entre artesanos y labradores solventes y la gestión del dinero a un administrador y varios consejeros designados entre la elite municipal. En la ciudad de Daroca, un artesano o labrador ejercía de cambrero o administrador del pósito asistido por cuatro diputados elegidos a partes iguales entre la oligarquía y los dos estratos pecheros representados en el concejo: dos ciudadanos, un artesano y un labrador. En la modesta ciudad de Albarracín, las Ordenanzas de 1567 y 1580 disponían que el precio de venta del trigo en el pósito fuese fijado por los cuatro regidores y doce consejeros municipales, elegidos mitad por mitad entre los ciudadanos y los sectores populares.

Con una clara intención de proteger al consumidor y cimentar la demanda interna, el surgimiento de las cámaras modifica el control del concejo sobre los intercambios de grano. La intervención habitual en este mercado se hallaba limitada en la época medieval a regular los sistemas de pesos y medidas, la molienda o la panificación. La injerencia más directa en el mercado era ocasional y reservada a las épocas de carestía, tras constatarse la existencia de serias alzas de precios en el Almudí3 ${ }^{33}$. Las compras de cereal, costosas y difíciles, eran acompañadas de diversas medidas para asegurar el abasto: ayudas o préstamos a particulares que aportasen grano al mercado público, prohibiciones de extraer trigo de la localidad, requisas, tasaciones y multas contra los revendedores. Estas disposiciones tenían un efecto limitado al proliferar el acaparamiento y la especulación.

30. MATEOS, José Antonio, «The making...», pp. 134-136.

31. Así se documenta de forma explícita en MATEOS José Antonio, «Municipio y mercado en el Aragón moderno: el abasto de trigo...» pp. 37-39; URZAY, José Ángel, SANGÜESA, Antonio, e IBARRA, Isabel, Calatayud...pp. 137-145 y Biblioteca Universitaria de Zaragoza, H-10-54, fol.83-87

32. SAn ViCEnTE, Ángel, Colección ..., pp. 292-293, 299, 307, 545-546; MATEOS, José Antonio, Auge... pp. 280-282, 352-353 y «Municipio y mercado en el Aragón moderno: la Cámara del Trigo...», pp. 63.

33. FALCÓN, María Isabel, «La comercialización del trigo en Zaragoza a mediados del siglo XV», Aragón en la Edad Media, I, (1977), pp. 242-244; MATEOS, José Antonio, «Sobre tasas y monedas, ferias y usuras: municipio y mercado en Daroca bajo Juan II y Fernando el Católico (1459-1516)», Aragón en la Edad Media, XIII, (1997), pp. 204-205 y MEDRANO, Javier, Puertomingalvo..., pp. 272-275. 


\section{Gráfico 1.Ventas de trigo por los positos de Barbastro y Daroca (1518-1707)} -En cahíces-

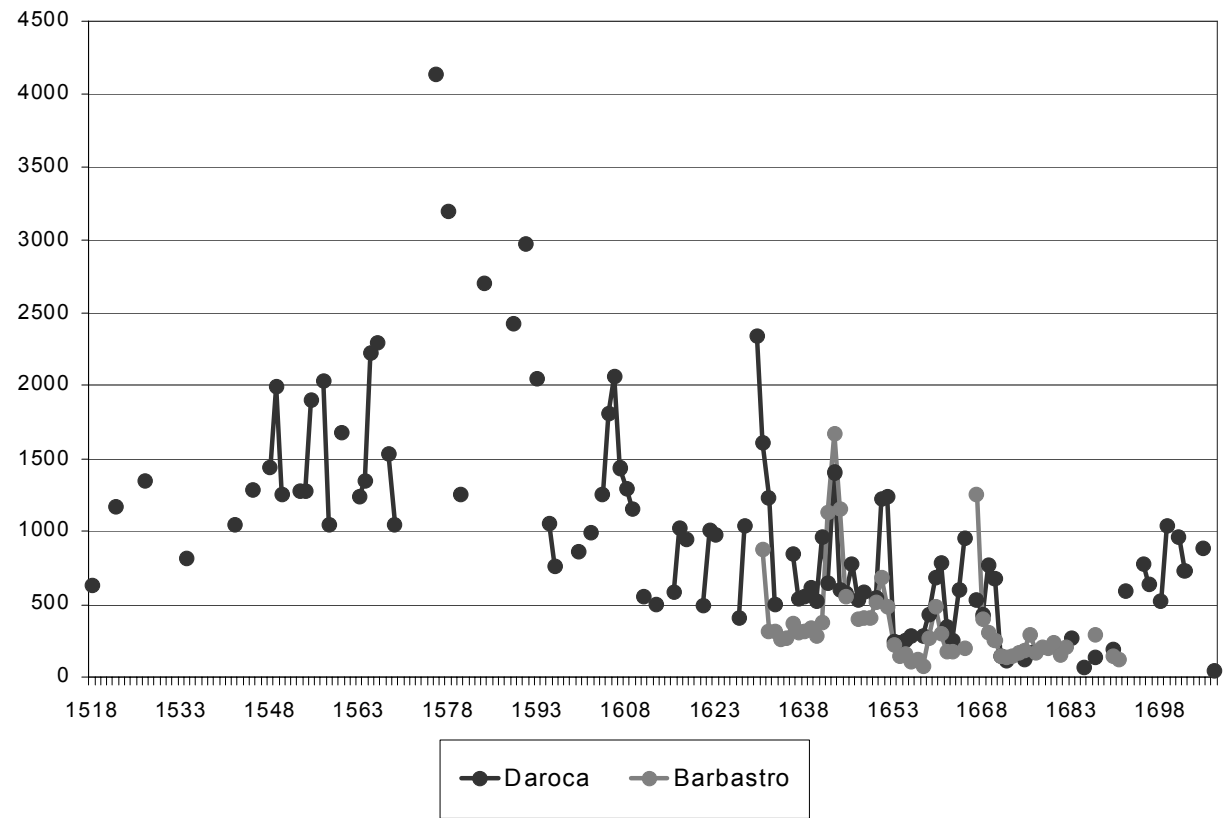

Fuentes: SAlAS, José Antonio, La población..., p. 348 y MATEOS, José Antonio Auge.., pp. 487-489.

Al dotarse de existencias de cereal permanentes, preservadas durante el invierno gracias al predominio de un clima frío y seco, las cámaras surgidas durante el Quinientos otorgan a los concejos un control más directo y constante sobre el mercado; pero presentan gran fragilidad frente a bruscas alteraciones de precios. La renovación de las existencias se convirtió en un problema endémico. Con anterioridad, tras venderse el grano en años de escasez a un precio idéntico o inferior al de compra, los remanentes se ofrecían a un precio rebajado, pero rara vez se trataba de sumas considerables. Frente al libre abasto de grano por las panaderías vigente en época medieval, la necesidad de vender las existencias impuso hacia mediados del siglo XVI vincular su suministro al pósito ${ }^{34}$, medida posible al constituir éstas bienes de propios y carecer de las fuertes trabas al control municipal que las concesiones privilegiadas imponían

34. Gómez De Valenzuela, Manuel, Documentos...ppp. 259-266; SAlas, José Antonio, La población...p. 99; MATEOS, José Antonio, Auge... pp. 274-279, 490 y «Municipio y mercado en el Aragón moderno: el abasto de trigo...» pp. 52-55; URZAY, José Ángel., SANGÜESA, Antonio, e IBARRA, Isabel, Calatayud... pp. 139-140. Pese a su utilidad para dar salida a las existencias de trigo, los pósitos sólo asumían el abasto de las panaderías como su función principal en las principales ciudades de Aragón (Zaragoza, Huesca, Calatayud), mientras que en los restantes núcleos solían compaginar esta actividad con la venta de trigo a particulares para su cocción en hornos. 
en los hornos ${ }^{35}$. Con la salida de los excedentes asegurada por la creciente demanda de grano y el control de las panaderías, los pósitos aprovecharon el consenso social en torno al mercado y el aumento de la producción de cereal en el Quinientos ${ }^{36}$ para potenciar sus ventas, con especial vigor en las ciudades -véase el gráfico 1-, hasta culminar a fines de la centuria ${ }^{37}$.

Desarrollada en el entorno inmediato, la consecución del grano era confiada por los cambreros a delegados ${ }^{38}$. Si bien la participación de grupos acomodados como abastecedores era notable, la mayor regularidad y volumen de la demanda generados por la política municipal permitían la participación de sectores sociales más amplios -pequeños labradores, artesanos, trajineros- $y$ facilitaban su incorporación al mercado. Conforme crecieron las compras de los pósitos desde mediados del siglo XVI, los grandes comerciantes de Zaragoza ganaron importancia como proveedores de las ciudades $^{39}$. Estos controlaban el mercado de grano al haber arrendado a la Iglesia y nobleza la percepción de diezmos y derechos señoriales. Sus compras de trigo adelantado como préstamo al fiado sobre la futura cosecha constituyeron una práctica corriente, sobre todo desde fines de siglo XVI al crecer el endeudamiento campesino. Tras obtener el grano y almacenarlo en silos cercanos a los núcleos de producción, estos comerciantes esperaban el alza de precios en los meses previos a la siega para ofertarlo en el mercado. Sus prácticas especulativas en años de escasez llevaron al concejo de Zaragoza a obtener en 1578 un breve papal contra los acaparadores de grano y a decretar en 157677, 1592-93, 1595, 1606, 1614, 1630 y 1651 el Privilegio de los Veinte para forzarles a entregar sus existencias mediante la actuación de un tribunal de excepción privativo de esta ciudad; pero su integración en la oligarquía dirigente les valió un trato benigno en estos casos. Presionados por su endeudamiento, incluso ciertos pósitos recurrieron a adquirir trigo adelantado desde fines del siglo XVI y en la primera mitad del siglo

35. Pallaruelo, Severino, Los molinos del Alto Aragón, Huesca, 1994, pp. 132-137; MATEOS, José Antonio, Auge... pp. 274-279 y «Municipio y mercado en el Aragón moderno: el abasto de trigo...» p. 56.

36. LATORRE, José Manuel, «La producción agraria en el obispado...» pp. 131-132 y DiARTE, Pascual, $L a$ Comunidad de Daroca. Plenitud y crisis (1500-1837), Daroca, 1993, pp. 143-144.

37. SAn ViCENTE, Ángel, Colección..., pp. 543; SALAS, José Antonio, La población...pp. 95-101; MATEOS, José Antonio, Auge... p. 48; «Municipio y mercado en el Aragón moderno: el abasto de trigo...» pp. 50-52 y «Municipio y mercado en el Aragón moderno: la Cámara de Trigo...», pp. 60-61; URZAY, José Ángel., SANGÜESA, Antonio, e IBARRA, Isabel, Calatayud...pp. 139-140. Para este proceso en Castilla, Bennassar, Bartolomé, Valladolid...pp. 65-70, Chacón, Francisco, Murcia ..., pp. 364-365 y MarTineZ RUIZ, José Ignacio. Finanzas... pp. 178-180.

38. SALAS, José Antonio, La población...pp. 97-102; INGLADA, Jesús, «El intervencionismo municipal ante las crisis de subsistencias y epidémicas del siglo XVII, según las cartas misivas de la ciudad de Huesca» Argensola, 97, (1984), pp. 62-73; MATEOs, José Antonio, Auge... pp. 279-299; OTERo, Félix, La Vila de Fraga al segle XVII, Calaceite, 1994, vol. I, pp. 34-36, 146.

39. GómeZ Zorraquino, José Ignacio, La burguesía mercantil...pp. 59-64; MATEOS, José Antonio, Auge... pp. 289-292 y «Municipio y mercado en el Aragón moderno: el abasto de trigo...» pp. 41-43. Sobre el importante papel desempeñado por los comerciantes en el abasto de las ciudades castellanas, BENNASSAR, Bartolomé, Valladolid... pp. 65-70; RINGrose, David R. Madrid...pp. 178-180 y MARTINEZ RuIZ, José Ignacio, Finanzas... pp. 179-180. 


\section{Gráfico 2. Evolución del precio del trigo en Zaragoza, Daroca, Barbastro y Fraga (1500-1707) -En sueldos por cahíz-}

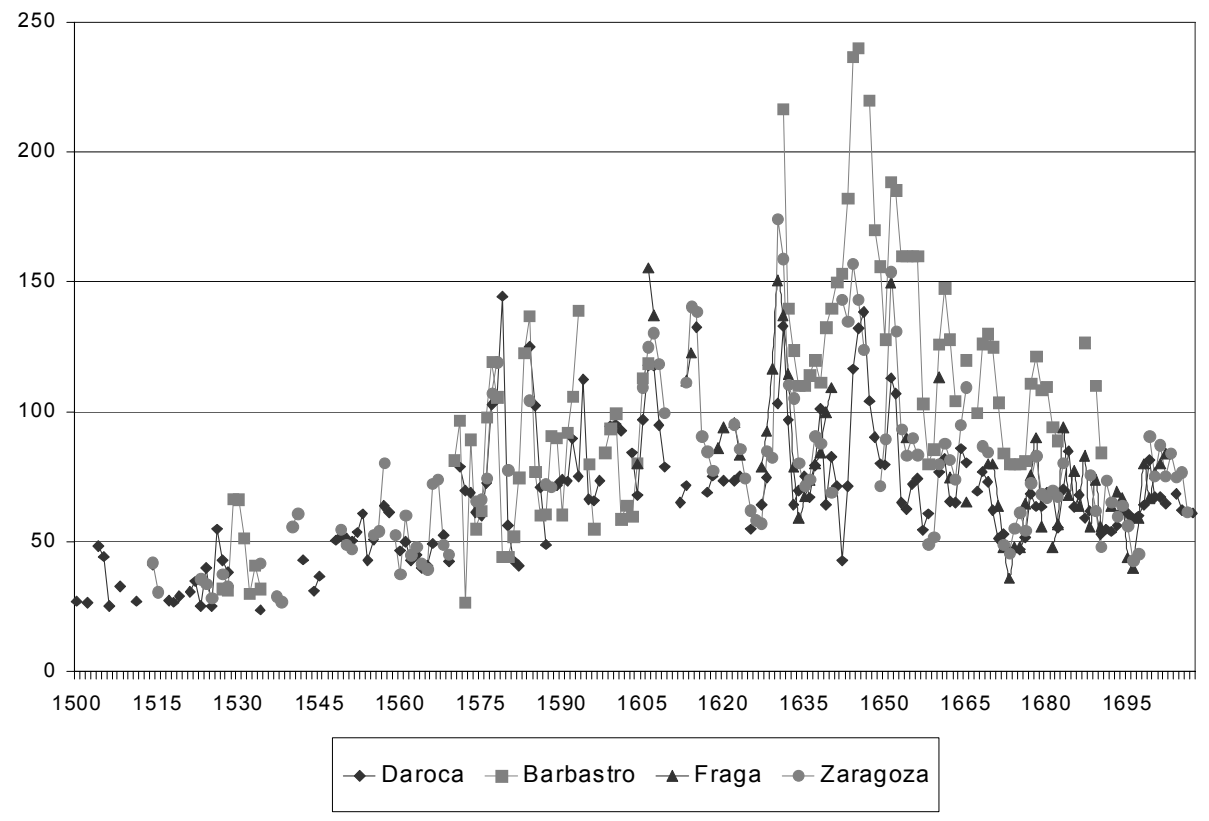

Fuentes: Sobre Barbastro, SALAS, José Antonio, La población...,pp. 101, 348 y «La incidencia social y coste económico de la peste de 1531 en Barbastro», Estudios, 80, (1983), pp. 36-37; Para Daroca, Mateos, José Antonio, Auge.., pp. 494-497. Para Fraga, OTERo, Félix, La Vila..., vol.1, p. 144 y Berenguer, Antonio, «Un ejemplo para el estudio de los libros de cofradías de oficios: la cofradía de San Joseph de Fraga», Argensola, 107, (1993), p. 245. Para Zaragoza, Archivo Municipal de Zaragoza, Actas Municipales, 15131697, Bastardelos, 1550-1706, Libros de contratos (795) y Cajas 479-482, 492, 495, 7765 y 7887.

Nota: el cahíz de Zaragoza equivale a 140 kilogramos ó 179,36 litros y comprende ocho fanegas.

XVII a sus vecinos labradores en aras de reducir los costes de adquisición y lograr una gestión más rentable ${ }^{40}$.

El progresivo aumento de las existencias resultante de expandir las adquisiciones entrañaba graves riesgos. Las mayores pérdidas venían ocasionadas al comprar el pósito grano a altos precios en períodos de escasez y descender su valor de forma brusca tras la siega: si el precio de venta no bajaba lo suficiente, panaderos y particulares se abastecían por su cuenta ${ }^{41}$. Aunque se pretendió evitar su adquisición en momentos de muy fuerte demanda mediante el aumento de las reservas, el temor de las autoridades

40. Mateos, José Antonio, Auge... pp. 300-310 y «Economía...».

41. Salas, José Antonio, La población...p. 98 y Mateos, José Antonio, Auge... p. 292 y «Municipio y mercado en el Aragón moderno: el abasto de trigo...» pp. 43, 53-55. 
públicas a carecer de grano para afrontar carestías que podían prolongarse varios años animaba a practicar nuevas compras. Esta gestión provocaba que las pérdidas sólo pudieran compensarse a muy largo plazo y con grandes dificultades, pese al creciente volumen de cereal suministrado, al ser los beneficios escasos por situarse el precio de venta del trigo a la población muy próximo al de su adquisición por el pósito ${ }^{42}$. Esta contención se guardaba en el trigo entregado a panaderos ya que su precio de venta fijaba el peso del pan vendido a la población a determinado precio: en años normales, la administración de Zaragoza cargaba a mediados del siglo XVI sólo un sueldo por cahíz.

Con estas premisas impuestas por su gestión, las oscilaciones de los precios del grano en el mercado resultaban fundamentales para la subsistencia financiera de los pósitos. Su evolución durante los siglos XVI y XVII en Aragón ha sido expuesta en el gráfico 2 mediante las mejores series disponibles, relativas a los núcleos de Zaragoza, Daroca, Barbastro y Fraga. Su análisis demuestra que el sistema de abastos municipal se vio sostenido en las décadas centrales del siglo XVI por el espaciamiento de los años de escasez y a una estable progresión de los precios a cuyo mantenimiento cooperaba la actuación de los pósitos sobre el mercado ${ }^{43}$. Generadas de forma probable por la aparición de rendimientos decrecientes en las cosechas, las serias carestías (1570-72, 1576-80, 1584-85, 1591-94) acaecidas en las tres últimas décadas del siglo provocaron oscilaciones muy bruscas de precios en el mercado de grano que desajustaron el mecanismo de abasto. El impacto de súbitos aumentos de los precios en estos años, favorecido por su condición de territorio interior y la competencia de los pósitos, vino agravado por la compra de grandes cantidades de trigo y la renuncia a todo beneficio. Las existencias debían venderse al año siguiente a un precio muy inferior al de su adquisición y se produjeron serias pérdidas. Si ya los concejos solían contratar censales en años de carestía para comprar grano durante el siglo XVI, el abasto en estas décadas exigió un recurso más constante al crédito. Esta gestión resultó demasiado gravosa para unas haciendas municipales cada vez más endeudadas y terminó imponiendo una administración más rentable en el siglo XVII.

\section{EL SIGLO XVII}

Frente a la panorámica trazada para el siglo XVI, la centuria siguiente se halla presidida en Aragón por un perceptible declive económico. Si ya a fines del siglo XVI se perciben claros síntomas de estancamiento, propiciados por el carácter extensivo del crecimiento agrícola que provocó el agotamiento de las tierras cultivadas y la aparición

42. MATeos, José Antonio, Auge..., pp. 289-291 y «Municipio y mercado en el Aragón moderno: el abasto de trigo...», pp. 53 y A(rchivo) M(unicipal de) Z(aragoza), Act(as) Mun(icipales), 1523, 7 de diciembre, 1525, fol.208v-211r, 220r-224r, 1549, 16 y 21 de octubre, 1561, 19 de marzo.

43. La política de abastos municipal podría contribuir en ciertos territorios a la moderada revolución de los precios en España entre 1550 y 1625 expuesta en MARTIN ACEÑA, Pablo, «Los precios en Europa durante los siglos XVI y XVII: estudio comparativo», Revista de Historia Económica, X, 3, (1992), pp. 368-370. 
de rendimientos decrecientes, la expulsión de los moriscos en 1610 añadió una sangría poblacional y un serio golpe al mecanismo de detracción señorial laico que repercutió en toda la economía aragonesa y dañó en especial al sistema financiero ${ }^{44}$. El continuo declive experimentado por la producción industrial y artesanal, que alcanzó especial gravedad durante la segunda mitad de la centuria, se vio precipitado por la retracción del capital mercantil aragonés a fines del siglo XVI y principios del XVII ${ }^{45}$. Ejercido el control de las principales transacciones en el reino por comerciantes genoveses en 1580-1620 y franceses a partir de esta última fecha, la recuperación de la burguesía mercantil aragonesa en la segunda mitad de la centuria no excluyó la presencia de mercaderes franceses y mostró una orientación más rentista y menos comercial ${ }^{46}$. La invasión de piezas forasteras falsas, defectuosas o de menor ley ${ }^{47}$, si bien agilizó los intercambios al ofrecer al mercado un numerario mejor adaptado al valor real de la plata, generó problemas de conversión entre las distintas monedas utilizadas y favoreció en ciertos períodos la inflación de los precios de manufacturas y alimentos. La mayor presión fiscal desplegada por la monarquía ${ }^{48}$ y otras instituciones aragonesas mermó la capacidad adquisitiva de la población y modificó la intervención pública sobre los mercados.

Este estancamiento demográfico y económico generó una contracción de la demanda interna de productos agrarios perceptible en el descenso de su precio -véase el gráfico 2- desde mediados del siglo XVII, que aceleró la reestructuración de la economía del reino. Tras descender durante la primera mitad del siglo XVII, con especial énfasis en los cereales, la producción agraria creció y se remodeló desde mediados de la centuria ${ }^{49}$. La especialización productiva comarcal en artículos de fácil comercialización como el vino o el aceite ya detectada a fines del siglo XVI ó principios del XVII

44. SALAS, José Antonio, «La evolución demográfica...». Los efectos de la expulsión de los moriscos sobre la hacienda señorial en Aragón, en ABADIA, Alejandro, La enajenación de rentas señoriales en el reino de Aragón, Zaragoza, 1998, pp. 303-449.

45. REDONDO, Guillermo, Las corporaciones de artesanos de Zaragoza en el siglo XVII, Zaragoza, 1982 y PEIRÓ, Antonio, «Comercio de trigo y desindustrialización: las relaciones económicas entre Aragón y Cataluña» en Las relaciones económicas entre Aragón y Cataluña (siglos XVIII-XX), Huesca, 1990. pp. 41-51.

46. GómEZ ZORRAQUINO, José Ignacio, La burguesía mercantil... y Zaragoza y el capital comercial. La burguesía mercantil en el Aragón de la segunda mitad del siglo XVII, Zaragoza, 1987.

47. MATEOS, JoséAntonio, «Ideario mercantilista y reformas monetarias en Aragón (1674-1702)», Cuadernos aragoneses de economía, 16, 1, (2006), pp. 261-279.

48. Sobre la fiscalidad real desplegada en Aragón en el siglo XVII, SolANO, Enrique, Poder monárquico y estado pactista (1626-1652). Los aragoneses ante la Unión de Armas, Zaragoza, 1987 y SANZ, Porfirio, Politica, hacienda y milicia en el Aragón de los últimos Austrias entre 1640 y 1680, Zaragoza, 1997.

49. MoRENO, Antonio, «Población y producción agrícola en el Norte aragonés (1598-1820)», en Congreso de historia rural..., pp. 490 y LATORRE, José Manuel, «La producción agraria en el obispado...», pp. 131-146 y «La producción agraria en el sur de Aragón (1660-1827)», Historia Agraria, 41, (2007), pp. $10-21$. 
se afianzó durante la segunda mitad del Seiscientos ${ }^{50}$. Esta reestructuración aumentó usos ganaderos estantes en comarcas aptas como el sur aragonés -Albarracín, Teruel, Daroca y Alcañiz-, sobre todo en núcleos carentes de producciones agrícolas competitivas. Este proceso, que ahorraba mano de obra, incluyó la conversión de las tierras cultivadas menos fértiles en pastos y la creación de nuevas dehesas y asociaciones de ganaderos, sobre todo desde mediados de siglo ${ }^{51}$. La posibilidad de exportar la lana a los Países Bajos y Francia, máxime ante el serio retroceso de la industria textil autóctona, unida a la de comercializar la carne en Cataluña, Valencia o Zaragoza volvió atractiva la propiedad de reses para la burguesía mercantil de la capital aragonesa durante la segunda mitad de la centuria ${ }^{52}$.

Esta remodelación productiva no sólo derivó del afianzamiento de las ventajas comparativas tras reducirse la demanda interna, sino de la mayor extroversión de la economía aragonesa. Propiciada por la irrupción de capital mercantil extranjero y la creciente demanda exterior de materias primas, la producción agraria se vio impelida a la exportación ${ }^{53}$. Junto a la demanda de trigo y carne por Valencia o de lana y aceite por Francia habitual en Aragón en el siglo XVII ${ }^{54}$, Cataluña incrementó su consumo de materias primas aragonesas, antes incluso de iniciar su expansión manufacturera y comercial a fines de esta centuria ${ }^{55}$. El propio suministro de trigo, carne o aceite del ejército real asentado en Aragón en 1640-52 y acuartelado después en Cataluña durante las sucesivas guerras entre España y Francia (1635-59, 1667-68, 1674-78, 1683-84, 1689-97) consolidó esta tendencia, máxime al resultar este abasto exento del pago de derechos aduaneros en Castilla, Aragón y Cataluña ${ }^{56}$. Según demuestra el apoyo de las principales instituciones públicas aragonesas -como las Cortes o la Diputación del reino- a la exportación de materias primas ${ }^{57}$, este modelo económico extrovertido fue aglutinando los intereses de las elites locales hasta incidir en la política de abastos municipal.

Frente a esta crisis y reestructuración del modelo económico, la incapacidad de los concejos para allegar ingresos con que afrontar los crecientes gastos en la segunda

50. MAteos, José Antonio, Auge..., pp. 347, 358 y Peiró, Antonio, Especialización..., pp. 14-33.

51. MATEOs, José Antonio, Auge..., pp. 423-424 y «Municipio y mercado en el Aragón moderno: la Cámara del Trigo...», pp. 184-185 y CEAmanos, Roberto y MATEOS, José Antonio, Calanda en la Edad Moderna y Contemporánea, Teruel, 2005, pp. 99-101.

52. GómEZ ZoRRAQUINO, José Ignacio, Zaragoza ... pp. 85-86, 161-62.

53. REDONDO, Guillermo, «Las relaciones comerciales Aragón-Francia en la Edad Moderna: datos para su estudio en el siglo XVII», Estudios, 85-86, (1985), pp. 123-154; PEIRÓ, Antonio, "Comercio...»y TORRAS, Jaume, «La economía aragonesa en la transición al capitalismo. Un ensayo», en Tres estudios de Historia económica de Aragón, Zaragoza, 1982, pp. 9-32 y «Relaciones económicas entre Aragón y Cataluña antes del ferrocarril», en Las relaciones..., pp. 17-31.

54. REDONDO, Guillermo «Las relaciones...» y CASEY, James, El reino de Valencia en el siglo XVII, Madrid, 1983, pp. 81-103.

55. Vilar, Pierre, Cataluña en la España Moderna, Barcelona, 1978, vol.1, pp. 430-452.

56. Archivo de la Corona de Aragón, Consejo de Aragón, legajos 57-60.

57. PEIRÓ, Antonio, «Comercio de trigo...» pp. 40-42. 
mitad del siglo XVI se agravó en la centuria siguiente hasta volver insuficiente el perpetuo recurso a contraer créditos. El endeudamiento municipal forzó a elevar la presión fiscal y a enajenar bienes de propios y comunales, con frecuencia en provecho de las elites locales de ciudadanos e infanzones ${ }^{58}$. Al tiempo que la propiedad de la deuda censal fue transferida por estos grupos sociales al clero mediante ventas o donaciones, los concejos firmaron desde fines del siglo XVI concordias con sus acreedores para demorar pagos o reducir la tasa de interés y poder afrontar sus deudas ${ }^{59}$. Su revisión confirió la gestión de las haciendas a «conservadores» designados por los censalistas tras garantizar éstos a los concejos mantener su administración política y judicial, los propios y comunales.

Efecto añadido, el endeudamiento municipal resintió la gestión de los pósitos. En primer lugar, la mayor presión fiscal aplicada por la monarquía en 1628-52 (servicio de 1626, guerra de secesión catalana) obligó a muchos concejos a recurrir al pago en especie, en especial en trigo y otros cereales, amén de aceite y lana ${ }^{60}$. Favorecida por la demanda de trigo y cebada por parte del ejército castellano estacionado en Cataluña tras la guerra de secesión, esta práctica fue habitual en contribuciones y donativos durante toda la segunda mitad del siglo XVII ${ }^{61}$. En segundo término, los pósitos prestaron con frecuencia dinero a la caja central del concejo para paliar su déficit y sufragar su deuda censal ${ }^{62}$. Estas transferencias sólo demoraron la quiebra municipal; pero restringieron la actuación de los pósitos en detrimento de su control del mercado público e impusieron una gestión más rentable que perjudicó al consumidor y retrajo una demanda ya castigada por el declive demográfico y económico. Unida a una mayor presión fiscal municipal, que afectó en especial a los alimentos básicos, estas medidas redujeron el apoyo de amplios sectores sociales a la intervención municipal y alejaron las transacciones del mercado público. Cada vez más vinculada a la posesión de tierras o la adquisición de títulos de infanzonía ${ }^{63}$, la oligarquía local mostró un creciente desinterés por sustentar la demanda interna de grano al preferir su venta con destino a Cataluña y Valencia, con especial fuerza durante la segunda mitad de la centuria. La caída de los precios del grano -véase el gráfico 2- gestada desde mediados del siglo XVII sancionó este proceso económico al barrer los obstáculos impuestos por la nor-

58. SALAS, José Antonio, «De la euforia...», pp. 28, 31, 39, 49-50; MATEOS, José Antonio, «Propios...», pp. 57-61.

59. Sobre el tema, MATEOS, José Antonio, «Propios...», pp. 68-72.

60. Solano, Enrique Poder monárquico...pp. 54-56.

61. SANZ, Porfirio, Política, hacienda...

62. SAlAS, José Antonio, La población..., pp. 82-85; Olivo, Jorge del, «La evolución de la hacienda municipal de Calatayud durante el siglo XVII», Jerónimo Zurita, 76-77, (2002), pp. 228 y MATEOS, José Antonio, Auge..., pp. 183-186, 293-299, 457-458; «Municipio y mercado en el Aragón moderno: el abasto de trigo...», pp. 44-45 «Municipio y mercado en el Aragón moderno: la Cámara del Trigo...», pp. 82-84.

63. SALAS, José Antonio, La población...pp. 275-284, 296-304; JARQUE, Encarna, «La oligarquía urbana...», pp. 147-167; MATEOS, José Antonio, Auge..., pp. 81-102; GómEZ ZorRAQUINO, José Ignacio, «Ni señores...» y «Del concejo foral...» pp. 119-127. 
mativa consuetudinaria a la extracción de trigo y cebada del reino y facilitar el apoyo de las instituciones públicas aragonesas a su exportación ${ }^{64}$.

La cesión de los propios a los censalistas, la mayor presión fiscal real y municipal, la enajenación de bienes comunales y la contracción de la política de abastos aparejaron una ruptura de los pactos sociales adoptados durante el Quinientos, cuya reanudación se reveló más difícil y entrañó mayores concesiones a los grupos privilegiados, en especial al clero ${ }^{65}$. La evolución política local cooperó en este proceso. Desde fines del siglo XVI los principales cargos municipales se reservaron a una elite más exigua al imponerse mayores niveles de riqueza para su ejercicio al tiempo que artesanos y labradores vieron reducida su representación ${ }^{66}$. Al igual que los delegados de estos dos grupos sociales son apartados de la gestión de los pósitos, la supervisión de propios y comunales por los estratos más humildes representados en el concejo o asociaciones vecinales agrupadas por parroquias se restringió o desapareció ${ }^{67}$. Ante el declive del poder público, ganó terreno la órbita de lo privado. Las redes verticales se reforzaron mientras los vínculos horizontales del común se debilitaron, como revelan las tensiones entre maestros y oficiales artesanos por la promoción profesional o el control del mercado laboral ${ }^{68}$. Asentadas en el auge de las relaciones verticales, crecieron formas de extracción del excedente agrario y acumulación de capital desligadas de las cargas señoriales. El endeudamiento o la carencia de medios de producción impusieron al campesino un mayor sometimiento hacia las elites y una creciente exclusión de los beneficios de las transacciones ante la presión de propietarios, comerciantes y prestamistas $^{69}$. Como mecanismos de protesta, al vecino le restó la delincuencia, el destrozo de propiedades, la denuncia anónima y el fraude fiscal.

La remodelación del poder político local y la ruptura del consenso social en torno al mercado, así como la reestructuración de la economía aragonesa y los intereses de las elites rectoras fueron transformando la función de los pósitos. Las dificultades financieras municipales forzaron desde principios del siglo XVII a una política más pragmática -véase los gráficos 1, 3 y 4 - consistente en limitar las compras y ventas, reducir las reservas y gravar más el trigo proporcionado a particulares y panade-

64. PEIRÓ, Antonio, «Comercio de trigo...», pp. 40-42.

65. MAteos, José Antonio, Auge.., pp. 141-143, 281-282, 352-353 y «The making...» p. 136.

66. GÓMEZ ZorRAQUINO, José Ignacio, «Del concejo foral..., pp. 116-119.

67. REDONDO, G. «Cargos municipales y participación artesana en el concejo zaragozano (1584-1706)», Estudios, 76, (1976), pp. 159-190 y MATEOS, José Antonio, Auge..., pp. 100-118.

68. Redondo, Guillermo, Las corporaciones...; Mateos, José Antonio, Auge..., pp. 414-418; PeIRó, Antonio, Jornaleros y mancebos, Barcelona, 2002, pp. 51-60, 83-88, 131-147.

69. GÓMEZ ZorRaquino, José Ignacio, La burguesía mercantil... pp. 59-64 y Zaragoza..., pp. 86-88; MATEOS, José Antonio, Auge..., pp. 290-310 y «Municipio y mercado en el Aragón moderno: el abasto de trigo...», pp. 41-43. La consolidación de una mayor detracción de las elites sobre el campesinado resulta un proceso común en Europa durante la Edad Moderna, según AYMARD, Maurice, «Autoconsommation...» 
Gráfico 3. Evolución de las ventas y existencias de trigo en el posito de Zaragoza (1631-1700)

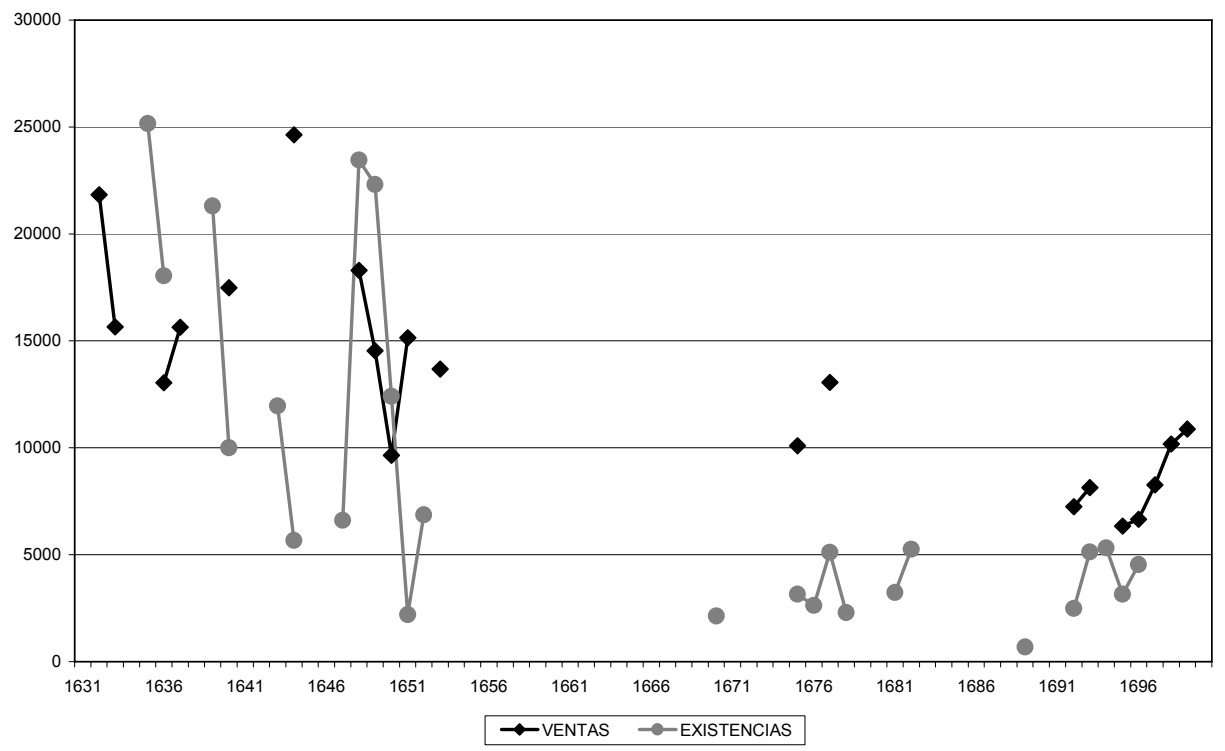

Fuentes: MATEOS, José Antonio, «Municipio y mercado en el Aragón moderno: el abasto de trigo...», pp. 46,48 .

ros. Sujeto a ritmos diferentes según los lugares ${ }^{70}$, este proceso resultó más lento en Zaragoza debido a la mayor demanda de grano y menor capacidad de abasto de sus habitantes. Ante las grandes crisis frumentarias padecidas en 1605-06, 1614-15, 163031 y 1651-52, los concejos aumentaron las compras de grano y renunciaron a todo beneficio en su venta; pero desde mediados de siglo consolidaron la reducción de sus existencias comenzada en sus inicios.

La contracción de la demanda interna de grano por el declive demográfico y el aumento de su productividad al centrarse su cultivo en las tierras más fértiles provocaron en la segunda mitad de siglo un nítido descenso de los precios -véase el gráfico $2-y$, junto con la menor incidencia de carestías, facilitaron una mayor remodelación de la gestión de los pósitos. Los concejos redujeron más las existencias almacenadas hasta un volumen adecuado para intervenir en el mercado local con un menor grado de apoyo social y poder apelar a una compulsión limitada sobre la población. Muchos pósitos restringieron o abandonaron la venta a particulares y ofertaron menos grano a las pana-

70. SAlAS, José Antonio, La población...pp. 101, 348; Otero, Félix, La Vila ..., vol. I, pp. 144, 147; MATEOS, José Antonio, Auge..., pp. 487-493, «Municipio y mercado en el Aragón moderno: el abasto de trigo...», pp. 44-52 y «Municipio y mercado en el Aragón moderno: la Cámara del Trigo...», pp. 65-67. 


\section{Gráfico 4. Evolución de las existencias de trigo en el posito de Daroca entregadas al finalizar el año administrativo (1516-1706) -En cahíces-}

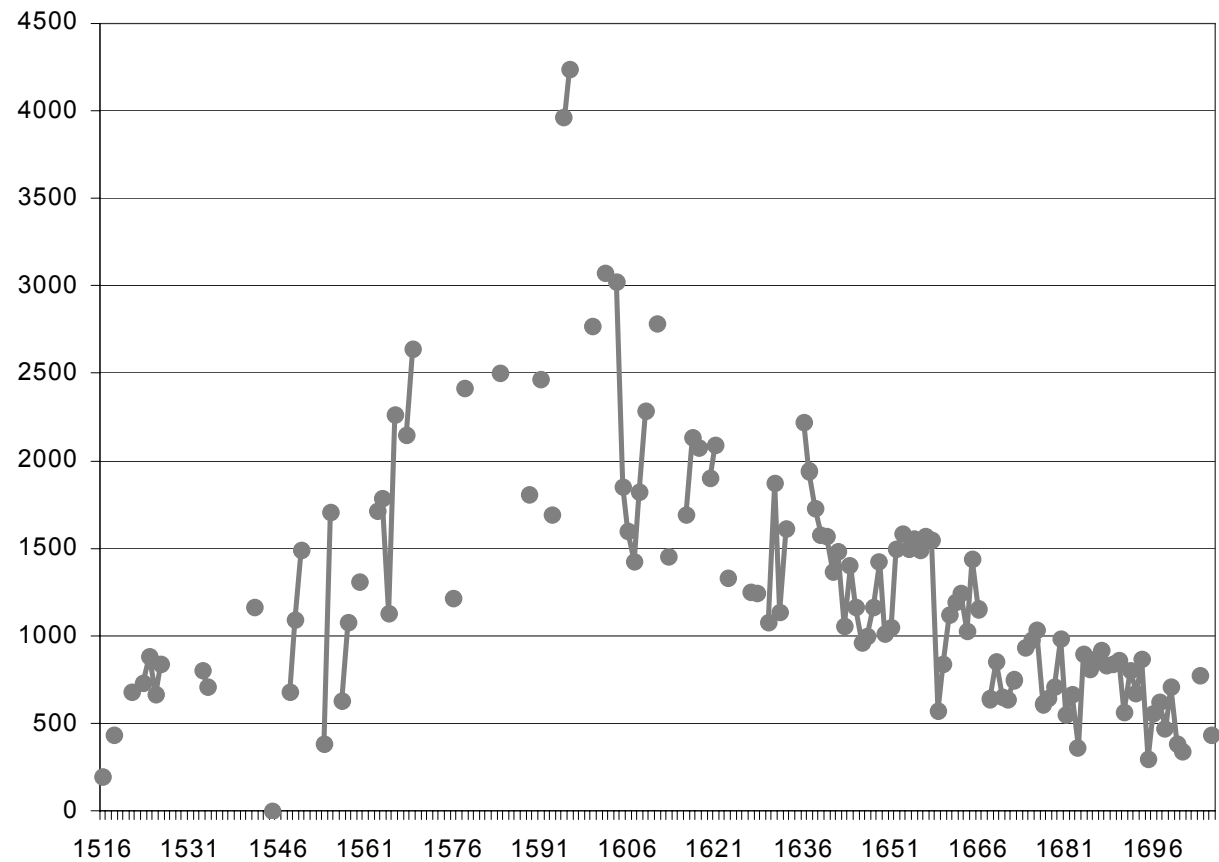

Fuente: MATEOS, José Antonio, Auge..., pp. 487-489.

derías $^{71}$. En las poblaciones dotadas de panaderías de pan franco, el abasto de trigo candeal -de mejor calidad-dedicado a su cocción ganó peso sobre el trigo destinado a pan común por sus mayores beneficios. El margen creciente desde principios del siglo XVII entre los precios de compra y venta de grano aumentó aún más desde mediados de la centuria, en especial en las grandes ciudades: durante la segunda mitad del siglo XVII en años sin problemas de abasto éste rebasaba los cuarenta sueldos por cahíz en Zaragoza y Daroca mientras en núcleos más modestos como Albarracín alcanzaba sólo los dos sueldos por fanega ${ }^{72}$. Consecuencia adicional, si desde mediados del siglo XVI el precio de venta del trigo en el pósito se convertía en valor de referencia para las transacciones y fijaba el coste público del pan en vez del Almudí, la mayor presión fiscal municipal ejercida en el siglo XVII provocó que el precio vigente en el mercado

71. SAlas, José Antonio, La población...pp. 101, 348; OTERo, Félix, La Vila ... vol. I, pp. 144, 147; MATEOS, José Antonio, Auge..., pp. 487-493, «Municipio y mercado en el Aragón moderno: el abasto de trigo...», pp. 45-49 y «Municipio y mercado en el Aragón moderno: la Cámara del Trigo...», pp. 65-67, 76-78.

72. OTERo, Félix, La Vila...vol.I, pp. 144, 147; MATEOS, José Antonio, «Municipio y mercado en el Aragón moderno: la Cámara del Trigo...» pp. 68-70, Auge..., pp. 293-295 y AMZ, Cajas 492, 495 y 8142. 
público de granos se alzase de nuevo como la principal referencia, con mayor claridad desde mediados de la centuria ${ }^{73}$. Al tiempo, el descenso de las existencias de grano -véase los gráficos 3 y 4- y el encarecimiento de las ventas limitó la actuación de los pósitos en el mercado, redujo su capacidad de respuesta frente a bruscas alteraciones de precios y restó confianza a los vecinos en su intervención.

El menor aporte de grano realizado por el pósito y su mayor coste indujo a los panaderos a comprar trigo en mayor cantidad por su cuenta para sus panaderías e incluso a cocer pan en las casas de sus clientes ${ }^{74}$. Forzados a aceptar un menor control del mercado que favorecía la especulación y perjudicaba a la calidad del pan, los concejos se resarcieron al aumentar los gravámenes del trigo vendido a las panaderías. Como en las principales ciudades europeas ${ }^{75}$, horneros y panaderos ganaron iniciativa en el mercado de grano, bien por medio de comisionados que adquirían grano en el entorno o por la oferta de trigo o harina por mercaderes y arrieros. Este avance de la esfera privada en el mercado de grano se tradujo en la agudización de los privilegios disfrutados por particulares e instituciones, como revela la solicitud de concesiones de hornos y panaderías al monarca, en especial bajo el reinado de Felipe IV (1621-65) ${ }^{76}$. Al restringir el control público, el desorden provocado por estos privilegios en el mercado del pan de la capital alcanzó proporciones tan graves que forzó al concejo a moderarlos o abolirlos ${ }^{77}$.

Ante su menor control, los concejos permitieron a particulares desarrollar ciertas iniciativas sobre el mercado de grano bajo su supervisión ${ }^{78}$. Zaragoza arrendó el abasto a todas las panaderías de la ciudad en 1659-69 y 1683-89 y permitió a sus habitantes en el último cuarto de siglo vender trigo y cebada en sus casas y graneros a un precio algo inferior al del Almudí. Con especial nitidez desde mediados del siglo XVII, el descenso de actividad de los pósitos aumentó el interés de los concejos por regular la actividad del Almudí -Fraga, Barbastro- y por crear o gestionar -Daroca, Albarracíncorretajes sobre las transacciones efectuadas en este espacio. Junto a nuevos ingresos, su control les confería prerrogativas y capacidad de intervención en los intercambios. Zaragoza intentó incluso en 1670 gestionar los derechos establecidos sobre el Almudí,

73. MAteos, José Antonio, Auge..., pp. 292-297, «Municipio y mercado en el Aragón moderno: el abasto de trigo...», pp. 48-49 y «Municipio y mercado en el Aragón moderno: la Cámara del Trigo...», pp. 87-88.

74. MAteos, José Antonio, Auge..., pp. 276-279 y «Municipio y mercado en el Aragón moderno: el abasto de trigo...», pp. 56-58.

75. Sobre París, Meuvret, Jean, Etudes..., pp. 209-215 y KaPlan, Steven L. Les ventres...pp. 141-149. Para Madrid, véase Ringrose, David R. Madrid..., pp. 178-180 y BERnARdos, José Ubaldo, Trigo castellano...pp. 67-87.

76. Archivo de la Corona de Aragón, Consejo de Aragón, legajos 75 y 180.

77. MATEOS, José Antonio, «Municipio y mercado en el Aragón moderno: el abasto de trigo...», pp. 56, 61-62.

78. OTERo, Félix, La Vila ... vol. I, pp. 35-36; SALAS, José Antonio, La población...pp. 97, 102-103; MATEOS, José Antonio, Auge..., pp. 297, «Municipio y mercado en el Aragón moderno: el abasto de trigo...», pp. 49 y «Municipio y mercado en el Aragón moderno: la Cámara del Trigo...», pp. 87-88. 
regalía desde la Edad Media, a cambio de sufragar una suma anual a la hacienda real. Fracasado su intento, optó por su arriendo temporal para vender su usufructo a particulares $^{79}$.

Las nuevas circunstancias económicas y la reorientación de los pósitos acarrearon medidas adicionales, ligadas con frecuencia a la necesidad de renovar el trigo almacenado. Las malas cosechas de fines del siglo XVI y principios del XVII ya promovieron ventas de trigo al fiado a vecinos o prestamos para su devolución tras la llegada de la cosecha ${ }^{80}$. Si bien los pósitos alternaron ambos recursos en la primera mitad del Seiscientos, el descenso de la demanda de grano desde mediados de siglo aumentó su intensidad. La distribución de trigo en meses previos a la siega se convirtió en la actividad principal de ciertos pósitos ${ }^{81}$. Daroca repartía con carácter forzoso un mínimo de cuatrocientos cahíces anuales entre sus vecinos pecheros hasta optar por la venta al fiado a fines del siglo XVII al crecer la población. A la inversa, con toda probabilidad para reducir gastos, Albarracín sustituyó desde 1690-92 las ventas de trigo por su reparto. Otros concejos sitos en villas y ciudades -Fraga, Huesca y Barbastro- o pequeños lugares -Langa, Baraguas- ofrecían en sus cámaras de trigo durante el otoño a sus vecinos labradores la venta de grano al fiado o su préstamo y devolución en especie para facilitar la sementera ${ }^{82}$. Tarea ocasional desde sus precedentes en la Baja Edad Media $^{83}$, la necesidad de muchos labradores llevó a los pósitos a asumir mayores funciones crediticias durante las últimas décadas del siglo XVII. Ventas al fiado, repartos y préstamos de grano incluían el cargo de un canon modesto en concepto de gestión, ocasionaron frecuentes problemas de percepción hasta el punto de imponer el uso de cobradores y una cierta selección de los beneficiarios de la ayuda municipal en función de su nivel económico y status social.

79. SALAS, José Antonio, «La hacienda real aragonesa en la segunda mitad del siglo XVII», en FoRTEA, José Ignacio y CRemades, Carmen María (eds.), Politica y hacienda en el Antiguo Régimen, Murcia, 1993, pp. 492.

80. SAn ViCente, Ángel, Colección..., pp. 534-535; Otero, Félix, La Vila ...vol. I, pp. 39; Mateos, José Antonio, Auge..., pp. 292-297, «Municipio y mercado en el Aragón moderno: el abasto de trigo...», pp. 48-49 y «Municipio y mercado en el Aragón moderno: la Cámara del Trigo...», pp. 64.

81. MATEOS, José Antonio, Auge..., pp. 297-299 y «Municipio y mercado en el Aragón moderno: la Cámara del Trigo...», pp. 71. Estos repartos de trigo menudearon en pósitos emplazados en otros territorios de las Coronas de Castilla y Aragón. Como ejemplos, Bernabé, David, Hacienda ...pp. 260-269, GuTIÉRREZ Alonso, Adriano, Estudio...pp. 245-246 y MARCos Martin, Alberto, Economía...vol.I, pp. 478.

82. SALAS, José Antonio, La población...pp. 107-108, 185-186, 192-193; InGLADA, J. «Los Montes de Piedad de Huesca: instituciones de crédito para los labradores necesitados. Análisis de su actuación en 1652 y 1683-1684», Argensola, 95, (1983), pp. 5-15; OTERo, Félix, La Vila ...vol. I, pp. 36-37; GóMEZ De VAlenZuela, Manuel Estatutos y Actos Municipales de Jaca y sus Montañas (1417-1698), Zaragoza, 2000, pp. 483-484.

83. Como ejemplo, tras la mala cosecha de 1477, diversos concejos aragoneses prestaron a sus vecinos labradores grano almacenado en los silos municipales, en ocasiones tras haberlo requisado entre la población. Véase Mateos, José Antonio, «Sobre tasas...», pp. 205 y Medrano, Javier, Puertomingalvo..., pp. 272 . 
Este mayor énfasis en el préstamo de grano se vincula a una línea de actuación dedicada a crear organismos de asistencia a labradores. Liderada por distintos grupos sociales e instituciones, su fundación respondía tanto a motivos económicos como a lazos de solidaridad, fines asistenciales o de mera contención del orden social ${ }^{84}$. Ya datadas en la Baja Edad Media, estas instituciones despertaron renovado interés desde fines del siglo XVI y se expandieron durante todo el siglo XVII, en buena parte debido a la dedicación de legados píos y al amplio apoyo del poderoso sector eclesiástico a este cometido. Ante este proceso, muchos municipios se limitaron a apoyar mediante donaciones de dinero, grano o tierras las fundaciones privadas existentes. Movidos por causas diversas, incluida la propia necesidad de crédito por parte del vecindario, algunos concejos optaron por crear y gestionar sus propios Montes de Piedad, como el fundado en la modesta villa de Quicena en 1601 o en la ciudad de Huesca en 1621. Sin embargo, lastrada por la debilidad financiera concejil y carente de un fuerte apoyo social, su gestión siguió las mismas pautas que las fundaciones privadas: limitación los créditos, selección de sus beneficiarios según su solvencia y cobro de un moderado gravamen para evitar problemas como los vividos por el Monte de Piedad de Huesca ${ }^{85}$, que vio crecer los impagos a sus préstamos de cereal un $252 \%$ entre 1652 y 1684. Como revela la actuación del Monte de Piedad de Barbastro en la segunda mitad del siglo XVII, la protección pública sólo se ampliaba por medio de estas instituciones al estallar de forma esporádica carestías de grano ante el temor municipal al padecimiento de graves desórdenes sociales o serias pérdidas demográficas ${ }^{86}$.

\section{EL SIGLO XVIII}

Durante el siglo XVIII, Aragón consolidó cambios estructurales ya gestados por la reestructuración económica vivida en la centuria anterior. Proceso facilitado por la supresión de las aduanas con Castilla, Valencia y Cataluña decretada en 1717 por la nueva dinastía borbónica, afianzó su condición de zona receptora de manufacturas foráneas y productora de materias primas, exportadas en especial hacia Cataluña y Valencia ${ }^{87}$. Unida a cierta recuperación del mercado interior vinculada al crecimiento demográfico ${ }^{88}$, esta extroversión creciente posibilitó una perceptible expansión agraria durante el Setecientos como evidencia no sólo la extensión de cultivos sino de los regadíos -con la ampliación del Canal Imperial de Aragón entre 1766 y 1790 como su obra más emblemática ${ }^{89}$ - para aumentar la productividad y asegurar un acceso más

84. PeIRÓ, Antonio, «Feudalismo...», GÓMEZ De VAlEnZUEla, Manuel, Estatutos...pp. 296-300, 331-332 y Gómez ZorRAQUiNO, José Ignacio, «Los montes de piedad y el crédito rural en el Alto Aragón en el siglo XVII», X Simposio de Historia Económica, Barcelona, 2005, (trabajo mimeografiado).

85. InGLADA, Jesús, «Los Montes de Piedad...», pp. 5-15.

86. SALAS, José Antonio, La población...pp. 107-108, 184-194.

87. TORRAS, Jaume, «La economía...» y «Relaciones económicas» y PEIRÓ, A. «Comercio...».

88. PÉreZ SARrión, Guillermo, Aragón en el Setecientos, Lleida, 1999, pp. 46-56.

89. PÉREZ SARrión, Guillermo, Agua, agricultura y sociedad. El Canal Imperial de Aragón (1766-1808), Zaragoza, 1984. 
estable al agua, que aminorase el riesgo de sequías. Resultado de estos esfuerzos, la producción agrícola creció y consolidó la mayor especialización local y comarcal iniciada en la centuria anterior, sobre todo en artículos de fácil comercialización como el aceite y el vino ${ }^{90}$. Sin embargo, la producción manufacturera aragonesa no superó el declive iniciado en el siglo XVII ${ }^{91}$ ni evitó el predominio de los textiles franceses en el mercado aragonés, sustituidos por paños catalanes en las últimas décadas del Setecientos. La fuerte presencia de capital mercantil foráneo en Aragón se prolongó todo el siglo XVIII, con un predominio de los comerciantes franceses en la primera mitad de la centuria, navarros en sus décadas centrales y catalanes en su último tercio ${ }^{92}$. Pese al crecimiento económico, el desigual reparto de la propiedad y la renta ligado a unas relaciones de producción feudales frenó las posibilidades de desarrollo y agudizó la polarización social, como evidencian el enorme poder del clero y el surgimiento de un amplio sector de jornaleros rurales y urbanos al crecer la población ${ }^{93}$.

Frente a este proceso, con un creciente interés de las elites por la exportación de las materias primas en vez de por la promoción de su demanda interior, la organización de la política local no ayudaba a conformar un sistema de abastos más favorable al consumidor. Pese a permitir a la monarquía un control efectivo sobre la designación de cargos municipales, las reformas borbónicas no sólo mantuvieron el cierre de las oligarquías locales consolidado en el siglo XVII, sino propiciaron una mayor presencia de la nobleza junto a los burgueses ciudadanos en los concejos ${ }^{94}$. Con especial énfasis en las ciudades, el dominio de las elites salió reforzado mediante medidas como el disfrute a perpetuidad de los principales cargos, la reserva de cierto número de puestos para la nobleza y la supresión de representantes de labradores y artesanos. Esta evolución política dificultaba la forja de consensos sociales sobre el mercado público como los gestados durante el siglo XVI, que incluyesen a los grupos pecheros de la población. Sólo tras la crisis de subsistencias de 1766, debido a la presión de la monarquía, los concejos asumieron nuevos delegados - diputados del común, síndico personero- encargados de

90. PEIRÓ, Antonio, «Comercio...» y Especialización...

91. Peiró, Antonio, «Comercio...», pp. 49-51 y PÉREZ SARrión, Guillermo, Aragón... pp. 200-220.

92. GÓMEZ ZORRAQUINO, José Ignacio, «La burguesía mercantil catalana y su presencia en Aragón (17701808)», Pedralbes, 8-1, (1988), pp. 405-423; Los Goicoechea y su interés por la tierra y el agua en el Aragón del siglo XVIII, Zaragoza, 1989 y «La expansión de las redes comerciales catalanas por Aragón durante el siglo XVIII», en PÉREZ PICAZO, María Teresa, SEgurA, Antoni y FERRER, LLorenç, (dirs.

), Els catalans a Espanya, 1760-1914, Barcelona, 1996, pp. 255-269.

93. AtienZA, Angela, Propiedad y señorio en Aragón, Zaragoza, 1993 y Peiró, Antonio, Jornaleros..., pp. 41-52.

94. Moreno, José Antonio, «Los municipios aragoneses tras la Nueva Planta», Revista de Historia Moderna, 13-14, (1995), pp. 165-184. y El poder local en Aragón durante el siglo XVIII. Los regidores aragoneses, entre la Nueva Planta y la crisis del Antiguo Régimen, Zaragoza, 2004. Para Zaragoza, SANCHEZ, Sergio, «La llegada de los Borbones: transformación y adaptación en la elite de gobierno de la ciudad de Zaragoza», en SALAS, José Antonio, (coord.), Migraciones y movilidad en el valle del Ebro (siglos XVI-XVIII), Leioa, 2006, pp. 83-104. 
supervisar los abastos en interés de la población ${ }^{95}$. Ya en el proceso de transición a un régimen liberal, la presencia de la nobleza entre las oligarquías municipales se aminoró ante la incorporación de grandes labradores, comerciantes o miembros de profesiones liberales.

Al no redimir su deuda censal ni sanear sus finanzas con rapidez, la debilidad de la hacienda municipal durante el siglo XVII se prolongó en la centuria siguiente e impidió a los concejos actuar con fuerza en el mercado. Reducida su capacidad de gestión de los propios por las concordias firmadas por sus acreedores desde esta centuria, la intervención municipal en el mercado de grano durante el siglo XVIII se vio limitada por las Juntas de censalistas ${ }^{96}$, cuya concepción de los abastos defendía cumplir con unos niveles mínimos para evitar alteraciones sociales sin perjuicio de cierta rentabilidad que asegurase la extinción de sus censales o el pago de sus pensiones. Intensificados por la introducción de la Única Contribución como impuesto estatal permanente en Aragón por la dinastía borbónica ${ }^{97}$, los altercados entre concejos y distintos grupos sociales por la presión fiscal municipal siguieron centrados en los principales abastos, alcanzaron especial gravedad en las ciudades y actuaron en detrimento del control público sobre el mercado ${ }^{98}$.

Sobre la debilidad financiera y deficiente control del mercado por parte de los concejos heredados del siglo XVII inciden las disposiciones del nuevo Estado borbónico relativas a la gestión de los pósitos y organización local del mercado. Su importancia se manifiesta en Aragón ya durante la guerra de Sucesión (1705-15), con especial virulencia en Zaragoza. En primer lugar, tanto la incautación de grano municipal por parte de ambos ejércitos como el recurso al pago en trigo y cebada por los concejos para sufragar las contribuciones de guerra impuestas por la monarquía borbónica redujeron las existencias de los pósitos ${ }^{99}$. En segundo término, como había actuado en Valencia en 1707, Felipe V decretó en Zaragoza ese año la libertad de amasar pan y suprimió la sujeción de las panaderías al pósito que había operado - con distinto grado de intensidad- durante los siglos XVI y XVII ${ }^{100}$. La necesidad financiera municipal indujo al Consejo de Castilla en 1712 a permitir al pósito vender trigo a los horneros

95. Gómez ZorRAQUINO, José Ignacio, «Del concejo foral...» p. 128.

96. Estas disputas se reflejan en las concordias remitidas a la Real Audiencia de Aragón para su aprobación por el Consejo de Castilla. Véase A(rchivo) H(istórico) P(rovincial de) Z(aragoza), sección concordias.

97. PEIRÓ, Antonio, «La hacienda aragonesa en el siglo XVIII», Cuadernos aragoneses de economía, 3 , (1978-79), pp. 119-131 y PÉREZ SARRIÓN, Guillermo, «Los efectos de la real contribución de Aragón en el siglo XVIII», en FerRER, José Antonio (dir.), El conde de Aranda y su tiempo, Zaragoza, 2000, vol.1, pp. 251-286.

98. Sobre el tema, MATEOS, José Antonio, «Conflicto político, ideario económico y control social: las instituciones públicas en Aragón (1746-75), Crónica Nova, 30, (2003-2004), pp. 431-463.

99. AMZ, Act. Mun., 1710, 27 de junio, 1711, 7 de enero, 18 de marzo, 10, 15 y 23 de abril, 1715, 26 de enero.

100. AMZ, Act. Mun., 1710, 27 de junio y cajas 462 y 495; AHPZ, Real Acuerdo, 1712, fol.67v-68v y A(rchivo de la) D(iputación) P(rovincial de) Z(aragoza), Intendencia de Aragón, manuscrito 792, fol. $43 \mathrm{r}-54 \mathrm{v}$, fol.76r-86v. 
con un módico beneficio, pero el libre amasijo no fue suprimido hasta abril de 1720 , cuando un decreto real restituyó al pósito de Zaragoza su control sobre la venta de pan tras limitar su margen de ganancia. Erigido en importante precedente, esta reforma temporal impulsó las actividades de comerciantes y panaderos en el abasto local, tónica mantenida durante toda la centuria.

Unido a medidas como el establecimiento de tasas sobre el trigo, requisas de existencias o prohibiciones de extraer grano, retomadas a nivel local al surgir carestías ocasionales en la primera mitad de la centuria ${ }^{101}$, este fuerte control del mercado dictado por la guerra perduró en ciertas nuevas atribuciones de las autoridades municipales borbónicas, como demuestra la regulación del precio de venta de trigo y cebada en el Almudí de Zaragoza por parte del corregidor durante el reinado de Felipe V, si bien su incidencia real parece decrecer con el tiempo ${ }^{102}$. Atenuado desde 1720 , este control estatal se recrudeció a mediados de siglo XVIII al introducirse durante el reinado de Fernando VI leyes destinadas a favorecer el tránsito de cereal en el interior de España que culminaron con el decreto de libre comercio de granos en 1765, ya bajo Carlos III $^{103}$. La supervisión del Estado mostró especial celo en Zaragoza a través de la Real Audiencia de Aragón, que informaba al Consejo de Castilla sobre la gestión del pósito ${ }^{104}$. Toda la remodelación de la gestión de este pósito durante la segunda mitad del siglo XVIII fue renegociada así entre el municipio de Zaragoza y el Consejo de Castilla a través de la Real Audiencia hasta 1808. Mantenido bajo administración francesa al ser ocupada la ciudad durante la guerra de Independencia (1808-14), la rápida adopción de la doctrina liberal por el concejo tras su cese determinó su extinción: propuesta por el municipio en mayo de 1815 la libertad de abastos de grano y otros comestibles, fue aprobada en septiembre de 1817 y la regulación del mercado realizada por el pósito durante toda la Edad Moderna llegó a su fin ${ }^{105}$.

De acuerdo con las líneas trazadas ya en la segunda mitad del siglo XVII, como se ha demostrado ya para otro importante mercado regional interior de grano en España como el de Castilla y León ${ }^{106}$, los pósitos gestionaron un escaso porcentaje del trigo

101. Por su importancia estratégica, estos recursos fueron frecuentes en Zaragoza. Véase AMZ, Act. Mun., 1711, 6 de marzo, 1715, 1 de enero. Sobre su extensión a otros núcleos aragoneses, RuJULA, Pedro y LAFOZ, Herminio, Historia de Borja: la formación histórica de una ciudad, Borja, 1995, pp. 180-181.

102. AMZ, Act. Mun., 1711, 23 de julio, 1715, 30 de julio y 15 de septiembre, 1721, 28 de abril, 1735, 22 de agosto, 1743, 3 de agosto.

103. Para una relación de esta normativa, véase CASTRO, Concepción de, El pan..., pp. 116.

104. En A(rchivo) H(istórico) N(acional), sección Consejos, libros 3855-3884, se recoge la contabilidad del pósito de Zaragoza para 1740-51, remitida por el municipio al Consejo de Castilla para su examen.

105. AMZ, Caja 73. La libertad de abastos se proclamó en Zaragoza con retraso frente a otras ciudades españolas: Madrid la adoptó en 1805 y Cádiz en 1806. Véase BERNARDOS, José Ubaldo, «Libertad e intervención en el abastecimiento de trigo a Madrid», en MARIN, Brigitte y VIRLOUVET, Catherine (dirs), Nourrir les cités..., pp. 381 y MARTINEZ RUIZ, José Ignacio, «El mercado internacional...», pp. 70.

106. LLOPIS, Enrique y JÉREZ, Miguel, «El mercado de trigo en Castilla y León, 1691-1788: arbitraje espacial e intervención», Historia Agraria, 25, (2001), pp. 53-54; RINGROSE, David R., Madrid..., pp. 136140, 178-179, 237-240; Bernardos, José Ubaldo, Trigo castellano...pp. 62-64, 111-123. 


\section{Gráfico 5. Evolución del precio del trigo en Zaragoza (1700-1808) -En reales de plata por cahiz-}

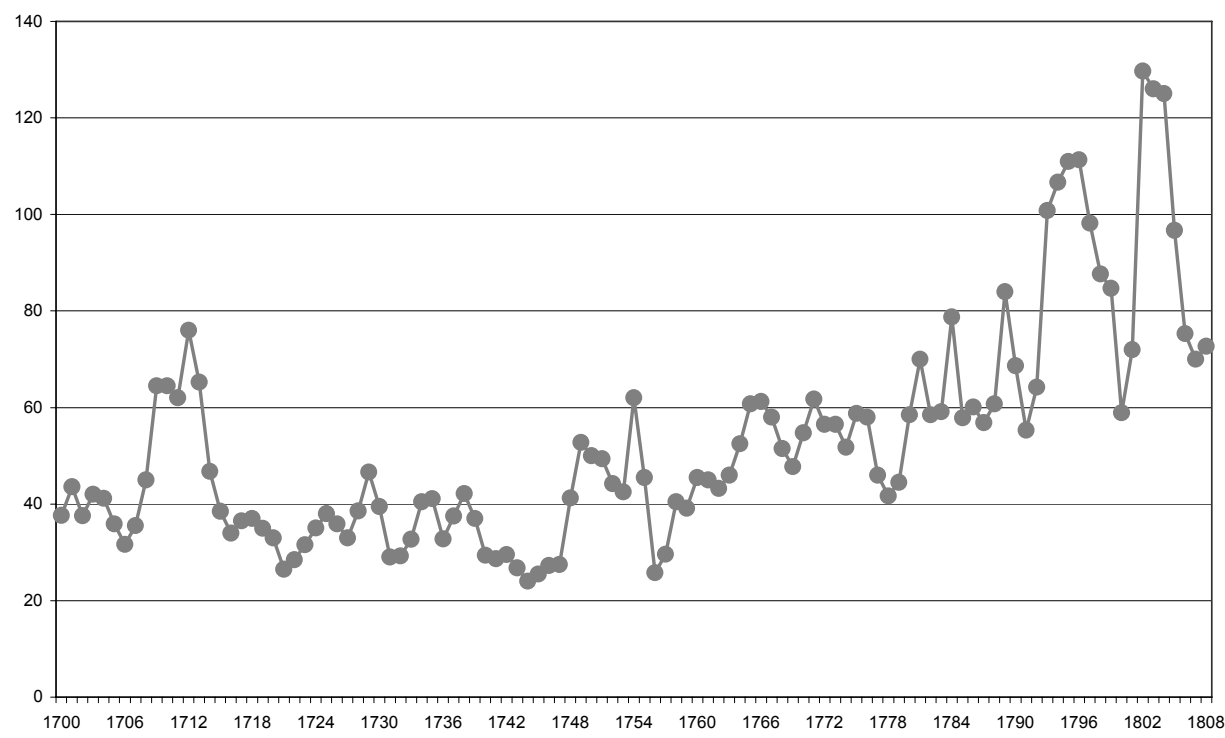

Fuentes: Archivo Municipal de Zaragoza, Bastardelos, 1700-1706, Actas Municipales, 1706-1808 y Cajas 462, 465-472, Archivo de la Diputación Provincial de Zaragoza, Contabilidad y Libros de Acuerdos de la Casa de Misericordia, 1701-1786, Archivo Histórico Nacional de Madrid, Sección Consejos, libros 38553884 y CASAMAYOR, Faustino Años políticos e históricos. De las cosas particulares sucedidas en la ciudad de Zaragoza, en Biblioteca Universitaria de Zaragoza, Manuscritos 106-142.

total comercializado en Aragón durante el siglo XVIII. Según refleja la evolución de las ventas realizadas por el pósito de Zaragoza expuesta en el Gráfico 6, esta modesta intervención sobre el mercado público contradecía el crecimiento de la demanda interna de grano experimentado durante las décadas centrales del siglo. Por este motivo, si bien los pósitos solían moderar sus beneficios ante carestías como las sufridas entre 1748 y 1755 ó en 1765-66 generaron respuestas poco eficientes y tardías en beneficio del consumidor. Las posibles pérdidas generadas por años de escasez se intentaban paliar aumentando un poco el gravamen en años de buenas cosechas; pero esta política dificultaba la venta de las existencias, en especial ante la fuerte orientación de horneros y panaderos a adquirir grano por su cuenta en el mercado público. En estas circunstancias, muchas críticas vertidas en la época sobre la gestión municipal de los pósitos revelan luchas entre instituciones por el poder local e incluso el deseo por parte de los acreedores de acceder a su administración al constituir una de las principales fuentes de ingresos municipales. En ocasiones, como ocurrió en Zaragoza en 1760-64 y 1770- 
78 , la presión de los censalistas consiguió obtener el completo control de los pósitos ${ }^{107}$; pero sus líneas de gestión no se alteraron demasiado.

Esta escasa capacidad de regular el mercado local por parte de los pósitos cobró una mayor importancia durante el siglo XVIII conforme aumentó la demanda de grano procedente de Valencia y en especial de Cataluña, ante la creciente integración del comercio interregional. Tras finalizar la guerra de Sucesión y derogarse en 1717 las aduanas interiores ${ }^{108}$ en las Coronas de Castilla y Aragón, la expansión económica y demográfica de Cataluña aumentó las exportaciones de cereal y carne aragoneses, así como de su lana y aceite en la segunda mitad de siglo, sobre todo hacia Barcelona ${ }^{109}$. Jerónimo de Uztáriz constató ya en 1724 el incremento y mayor complementariedad de los intercambios interregionales al observar que la escasez de grano y ganado en Cataluña se suplía con importaciones de Aragón y Castilla ${ }^{110}$, compras compensadas con los mayores beneficios generados por las ventas de productos textiles por catalanes en el interior peninsular. Si los mercaderes catalanes se instalaron en Aragón ya en la primera mitad del siglo XVIII, su asunción de las principales transacciones del reino a partir de 1770 en sustitución de comerciantes franceses y navarros reforzó este proceso $^{111}$. Favorecidas por la navegabilidad del río Ebro, acrecentada desde 1789 por la apertura del Canal Imperial, la comercialización de granos y otras materias primas resultó un fructífero negocio para las compañías comerciales catalanas asentadas en Aragón en la segunda mitad de la centuria.

Las consecuencias de esta creciente extroversión económica sobre el abasto local resultaron evidentes a mediados del siglo XVIII al elevar el crecimiento demográfico la demanda interna y externa de grano -véase la evolución de su precio en el Gráfico 5- y constatarse la escasa capacidad de retención de su producción agrícola por parte del campesino. Tanto los grandes comerciantes de granos, que arrendaban diezmos y derechos señoriales como los pequeños mercaderes, que prestaban dinero a los campesinos y se cobraban en trigo tras la llegada de la cosecha, almacenaban el grano adquirido a la espera bien de su alza de precio previa a la cosecha o su rentable exportación a Valencia o Cataluña a la vez que privaban a los labradores de excedentes para su

107. MATEOS, José Antonio, «Conflicto político...» pp. 449-451.

108. Sobre el carácter del incompleto desarme arancelario entre Aragón y Cataluña en el siglo XVIII y sus consecuencias para el tráfico interregional, TORRAS, Jaume, «Relaciones económicas...», pp. 17-31.

109. PEIRÓ, Antonio, «Comercio...», pp. 51-59 y GÓMEZ ZORRAQUINO, José Ignacio, «Las relaciones mercantiles entre Aragón y Cataluña en el siglo XVIII», en Las relaciones..., pp. 70-73 y «La expansión...», pp. 260-261.

110. UzTÁRIZ, Jerónimo de, Teórica y Práctica de Comercio y de Marina, Madrid, 1968, pp. 139.

111. Sobre la formación de estas redes mercantiles en Aragón, GóMEZ ZORRAQUINO, José Ignacio, «La burguesía mercantil catalana...» y «La expansión...», y PÉREZ SARRIÓN, Guillermo, «Compañías y redes mercantiles rurales en Aragón a fines del Antiguo Régimen: una aproximación microanalítica», en Els catalans..., pp. 271-284. 
comercialización $^{112}$. La amplia difusión de estas compras a crédito, sustentadas en el endeudamiento campesino, suscitó el interés de la monarquía por aumentar el número de pósitos públicos dedicados a prestar grano a los labradores desde mediados del siglo XVIII ${ }^{113}$ para evitar su empobrecimiento y la pérdida de sus medios de producción. Pese a estas disposiciones, que mostraron especial ahínco en Aragón en promocionar estos pósitos en la ribera del río Ebro, tanto su escasa presencia en ciertas comarcas ${ }^{114}$ como la escasez de sus fondos en dinero y grano limitaron su eficiencia en alto gra$\mathrm{do}^{115}$. Las fundaciones privadas con un propósito similar, cuyo número en Aragón en el siglo XVIII ha resultado ser muy superior al recogido en los propios informes del Estado borbónico ${ }^{116}$, realizaron préstamos de grano para la sementera en beneficio de labradores solventes similares a los ya practicados en la centuria anterior. Con todo, su actuación no pudo evitar el progresivo endeudamiento campesino que perpetuaba su dependencia respecto de los grupos más acomodados.

Con idéntica debilidad que estas instituciones, ante la insuficiencia del suministro de grano realizado por los pósitos públicos, los concejos concedieron mayor capacidad de actuación a grandes comerciantes y a otros particulares para abastecer los mercados y los mismos pósitos. Horneros y panaderos participaron de forma muy activa en este comercio hasta constituir su gremio en Zaragoza una institución con un peso creciente en las transacciones, que llegó a firmar asientos (1744-48, 1765-66) con el municipio para surtir de grano a las panaderías de la ciudad a cambio de un margen en los beneficios ${ }^{117}$. Con frecuencia, los pósitos adquirían trigo al fiado de comerciantes y propietarios de grano en detrimento de su libertad de acción sobre el mercado local. Los administradores del pósito de Zaragoza solicitaban cada año a fines del siglo XVIII de la nobleza titulada aragonesa y el Cabildo metropolitano la venta de grano

112. PÉreZ SARrión, Guillermo, Aragón...pp. 220-229. Con todo, los mismos pósitos prestaban en ocasiones dinero a los labradores a cambio de entregar trigo al precio medio del Almudí tras la cosecha para asegurarse un abasto más rentable. Véase el ejemplo de Zaragoza en AMZ, Caja 471, 1803, 6 de julio.

113. ANES, Gonzalo, «Los pósitos en la España del siglo XVIII» en Economía e ilustración en la España del siglo XVIII, Barcelona, 1969, pp. 71-94; CASTRO, Concepción de, El pan..., pp. 108-113; GIMÉNEZ, Enrique y MARTínEZ GOMIS, Mario, «La revitalización de los pósitos a mediados del siglo XVIII», en ForteA, José Ignacio y Cremades, Carmen María (eds.), Política:.., pp. 298-299. Muestra de este estímulo estatal, Borja creó en 1739 un pósito para prestar simiente a sus vecinos labradores. Véase Rujula, Pedro y Lafoz, Herminio, Historia... p. 181.

114. Entre las zonas que sufrían carencias de pósitos en Aragón a mediados del siglo XVIII destacaban las Cinco Villas, la ribera del Jalón, los Monegros, Belchite, la Litera y la Hoya de Huesca según ANZANO, Tomás, Discursos sobre los medios que pueden facilitar la restauración de Aragón, Zaragoza, 1768, p. 105.

115. PÉREZ SARRIÓN, Guillermo, Aragón...pp. 231-232. Un informe de la Real Audiencia en 1767 remitido al Consejo de Castilla aducía que los pósitos y Montes de Piedad no fructificaban en Aragón por la falta de financiación municipal. Véase AHPZ, Real Acuerdo, 1767, 13 de noviembre, fol.337r-347r.

116. PEIRÓ, Antonio, «Feudalismo...».

117. AMZ, Acuerdos de la Junta de Dirección de Propios, 1747, 27 de octubre, 10 de diciembre, Act. Mun., 1752, 22 de septiembre, 5 de octubre y Cajas 479 y 462. 
al fiado a un precio razonable, una vez recaudados los diezmos y rentas señoriales ${ }^{118}$. Ante su precariedad financiera, al igual que sucede en otras ciudades españolas ${ }^{119}$, el concejo de Zaragoza aceptó en ocasiones (1766-67, 1778-81) las propuestas de arrendar el pósito realizadas por comerciantes de grano o administradores de grandes casas nobiliarias. Ante la escasa capacidad de maniobra del pósito al padecerse carestías, algunos de los mayores comerciantes aragoneses -como Martín Zapater y Juan Martín de Goicoechea- con fuertes intereses en el mercado de grano se ofrecieron en 1789 y 1802 a realizar las adquisiciones necesarias de trigo importado de ultramar en Cataluña y trasladarlo por el río Ebro hasta Zaragoza ${ }^{120}$.

Más condicionada que en siglos anteriores por su extrema debilidad financiera, la gestión del pósito venía determinada por el precio de venta de su grano frente al situado en el Almudí1 ${ }^{121}$. Si la administración decidía obtener un beneficio modesto de los bajos precios del trigo comprado tras la cosecha, horneros y panaderos extraían trigo en grandes cantidades. Si era inferior su precio al del Almudí, como sucedía en años de carestía, ambos revendían parte de sus adquisiciones en detrimento del abasto local. Si el pósito encarecía el trigo por encima del valor del Almudí, con frecuencia para recuperar el dinero invertido en su compra, horneros y panaderos se abastecían en exclusiva en el mercado. Los concejos disponían entonces el registro de sus casas e inventario de su grano para repartir los excedentes del pósito e imponer penas a los infractores, que podían incluir la prohibición de amasar pan ${ }^{122}$. Norma común en la economía preindustrial, el peso del pan se reducía conforme aumentaba el precio oficial del trigo, que el municipio quería vincular a su venta en el pósito para negociar su monto con horneros y panaderos. Esta relación afectaba también al pan elaborado con trigo adquirido de forma fraudulenta o aún legal en el mercado: así los horneros y panaderos agremiados podían abastecerse en el Almudí de Zaragoza después de mediodía, tras dar prioridad al abasto por parte de los vecinos y las amasadoras y horneros no integrados en el gremio que vendían su pan en plazas públicas.

Al reinstaurar el pósito de Zaragoza en 1720, el Estado introdujo el principio de un beneficio moderado, que corroboraría en la concordia entre concejo y censalistas ratificada en 1741 al reiterar la necesidad de administrar el pósito «a coste y costas» ${ }^{123}$

118. AMZ, Cajas 468, 469, 470, 471 y 472.

119. Como ejemplo, véase el caso de Alicante en GIMÉNEZ, Enrique, Alicante...p. 299.

120. PEIRÓ, Antonio, Las Cortes aragonesas de 1808, Zaragoza, 1985, pp. 79-81, 92 y AMZ, Caja 468, 1789, 8 de mayo y Caja 471, 1802, 18 de febrero, 2 de junio.

121. AMZ, Act. Mun., 1749, 9 de enero, 29 de mayo, 1751, 11 de marzo, 13 de septiembre, 1753, 1 de febrero, 1757, 30 de abril, 14 y 23 de julio, 1758, 29 de mayo, 8 de junio, 2 de diciembre y cajas 463-465.

122. Estos problemas resultaban comunes en la gestión de los pósitos durante el siglo XVIII. Como ejemplos, GimÉnEZ, Enrique, Alicante...pp. 299-306 y Cremades, C.M. Alimentación y consumo... pp. 60-75. La ampliación del suministro ejercido por el pósito de Madrid en la segunda mitad del siglo XVIII hasta la liberalización del sistema de abasto en 1805 forzó una mayor sujeción de tahoneros para asegurar la salida de los excedentes. Véase BERNARDOS, José Ubaldo, «Libertad e intervención...», pp. 374-381.

123. AMZ, Act. Mun., 1741, 25 de octubre. 
-para sufragar los gastos de compras y gestión- sin generar ganancias al cabo del año. Pese a estas indicaciones, la debilidad de la hacienda municipal marcó otro rumbo a su gestión. Si bien moderaba su beneficio ante carestías, el pósito de Zaragoza mantuvo entre 1720 y 1750 un nivel notable de ganancias en la venta de trigo durante los años normales. La adquisición del grano por el gremio de horneros y panaderos se veía reforzada al permitir el concejo de Zaragoza la actividad marginal de amasadoras y amasadores no agremiados. Ante sus carencias de grano y caudal, que obligaban a comprar a crédito o pedir préstamos de dinero a corto plazo al 4 ó $5 \%$ de interés ${ }^{124}$, el pósito fue perdiendo capacidad de regular el mercado al actuar como un mero intermediario entre los propietarios y comerciantes a quienes adquiría trigo al fiado y los horneros a quienes se lo vendía ${ }^{125}$.

Al igual que sucedía en el resto de Aragón, conforme crecían los precios con la demanda de la población en la ciudad a mediados del siglo XVIII, la gestión del pósito de Zaragoza afectó en mayor medida al consumo urbano y suscitó mayores críticas de otras instituciones públicas. Así, la Real Audiencia de Aragón afirmaba en noviembre de 1750 que «no es pósito con fondo cierto, como los de Castilla, sólo es un tráfico de la provisión de tiendas de pan público» ${ }^{126}$. Tras considerar que permitía la especulación de horneros y panaderos para elevar sus beneficios en detrimento del consumidor, la Real Audiencia solicitó al Consejo de Castilla ya bajo Fernando VI -1750, 1752, 1755- el cese en Zaragoza del control municipal sobre la venta de pan y la imposición de la libertad de amasar: en principio reclamada como reinstauración de la orden real dictada en 1707, desde 1765 lo fue en estricta aplicación de la ley de libre comercio de granos proclamada ese año. Sus continuas críticas a la gestión municipal ante el Consejo de Castilla en los años sucesivos, que provocaron que éste concediese la administración temporal del pósito a la Junta de censalistas en 1760-64, agudizaron un desencuentro institucional sobre el abasto de grano en la ciudad que exacerbó los efectos de la crisis de subsistencias desatada en 1766.

Con indican las ventas de trigo por el pósito de Zaragoza en el siglo XVIII -véase el gráfico 6-, la proclamación del libre comercio de grano en 1765 demuestra haber limitado la intervención municipal en el mercado aragonés al restringir su actividad, justo cuando crecía la exportación de cereal hacia Cataluña y Valencia. En Zaragoza, este efecto se fue reforzado por la introducción del libre amasijo al estallar el motín del pan en abril de 1766, que obligó a las autoridades a derogar el abasto obligado de hor-

124. AMZ, Act. Mun., 1725, 20 de septiembre. Esta práctica se generalizó en los pósitos en la España del siglo XVIII. Para fines de la centuria, los casos de Madrid y Cádiz en BERnARDos, José Ubaldo, «Libertad e intervención...», pp. 380 y MARTINEZ RUIZ, José Ignacio, «El mercado internacional...», pp. 67-68.

125. AMZ, Cajas 462-467 y 495.

126. ADPZ, Intendencia, manuscrito 792, fol.43r-54v, 66r-86v y AMZ, Act. Mun., 1752, 22 de septiembre, 5 de octubre. 
neros y panaderos en el pósito ${ }^{127}$. Acabado el tumulto, las normas de gestión del pósito decretadas por el Consejo de Castilla a través de la Real Audiencia fijaron que éste debía limitarse a adquirir tras la siega unos 6.000 cahíces de trigo que suministraría a la población «a coste y a costas» en los meses previos a la siega con el fin de contener el alza de precios usual en este período. Este entendimiento fue fruto de una negociación con horneros y panaderos que abarcaba no sólo el precio de venta de grano, sino la capacidad de maniobra que el concejo permitiría a la actividad creciente de personas no integradas en el gremio para cocer y vender pan en la ciudad ${ }^{128}$. Su actuación fue utilizada con frecuencia por el concejo para forzar a los horneros a comprar grano en el pósito, pese a su resistencia en nombre del libre comercio. Modelo de gestión defendido por la Real Audiencia de Aragón en Zaragoza con especial vigor hasta 1780, su aplicación acarreaba riesgos de contraer pérdidas si se realizaba un abasto eficiente de la población e impedía generar beneficios con que ampliar los exiguos fondos del pósito, como evidencia la renuncia de la Junta de censalistas en 1778 a seguir administrando este organismo.

\section{Gráfico 6. Ventas de trigo por el posito de Zaragoza (1720-1808) -En cahíces-}

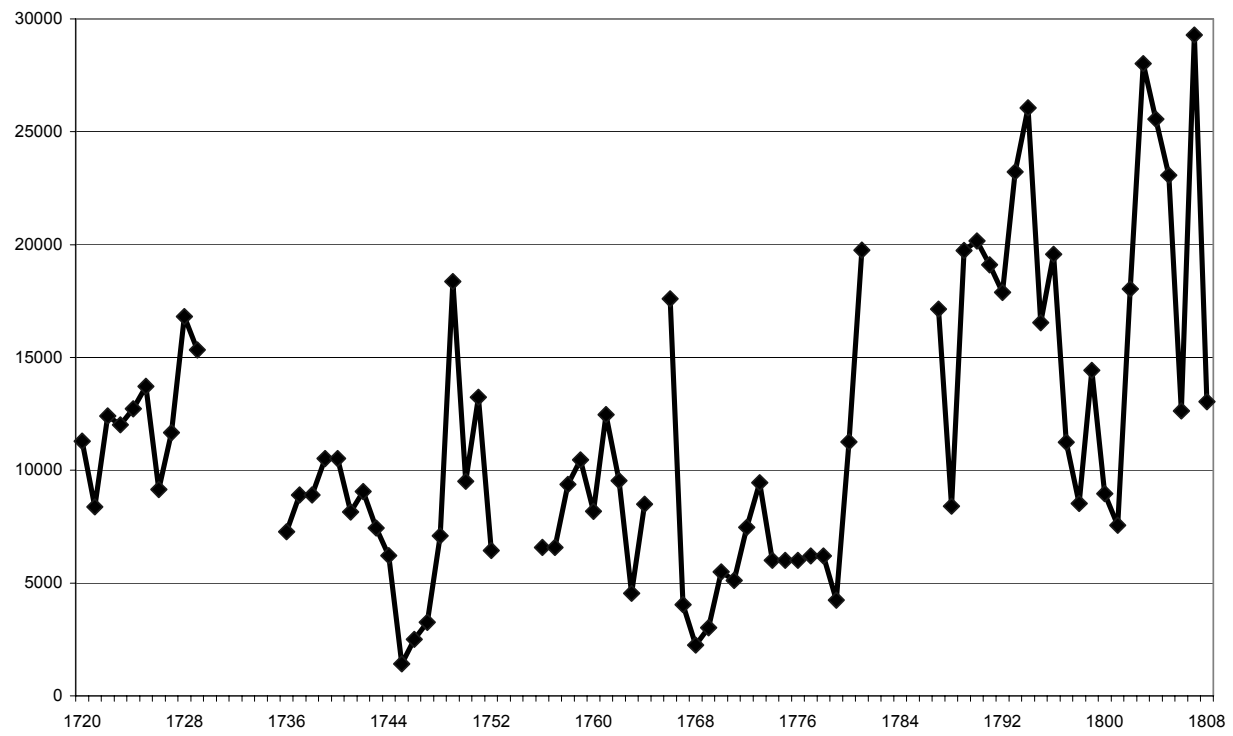

Fuentes: Archivo Municipal de Zaragoza, Cajas 462, 465-472 y Archivo Histórico Nacional de Madrid, Sección Consejos, libros 3855-3884.

127. Sobre este motín, BARAS, Fernando y MonTERO, Francisco José «Crisis de subsistencias y conflictividad social en Zaragoza: el motín de 1766», Estudios de historia social, 36-37, (1986), pp. 523-546. 128. AMZ, Cajas 463-466. Sobre el tema, MATEOS, José Antonio, «Conflicto político...», pp. 448-451. 
Con motivo de estos problemas, las décadas finales del siglo XVIII contemplaron en Zaragoza intentos de introducir una gestión del pósito más flexible y eficiente. Tras retomar el concejo el control del pósito en 1778, confiado a una Junta de graneros, la carestía de 1780 dio ocasión al intendente-corregidor Diego Navarro Gómez para ampliar su actividad e implantar en 1781 un nuevo modelo de gestión, que adecuaba el precio de venta del trigo al del Almudí1 ${ }^{129}$. Con este sistema, horneros y panaderos tenían menos facilidades para especular con el trigo del pósito: el pósito ya no reducía el precio de venta por debajo del vigente en el Almudí en los meses previos a la siega, estrategia que hasta ahora no sólo eliminaba los beneficios del pósito, sino que expandía las compras de los panaderos para su reventa en detrimento del abasto urbano. Al preservar sus ganancias, el pósito logró ampliar su liquidez y eliminar la dependencia de los préstamos a corto plazo, fijados a fines del siglo XVIII entre un 4,5\% y un $6 \%$. Con todo, esta reforma contó con sus detractores al entender que el pósito perjudicaba al consumidor al encarecer su acceso al grano para lograr mayores beneficios. Tras apelar a la legislación sobre libre comercio, el alcalde Gabriel Moreno consiguió clausurar el pósito y reinstaurar el libre amasijo de los horneros a principios de 1788. Con todo, la fuerte carestía desatada tras la cosecha de 1789 forzó a reabrir el pósito para abastecer de grano a la población.

Repuesta la gestión «a coste y costas» en 1789, el intendente Diego Navarro intentó en 1793 reimplantar la venta a precio del Almudí; pero la oposición de los delegados de estratos humildes (síndico personero, procurador general, diputados del común) logró suspender el sistema y dedicar sus beneficios a vender trigo a precio inferior al del mercado. Por fin, con el apoyo de la Real Audiencia, el nuevo intendente Blas Ramirez solicitó al Consejo de Castilla en junio de 1802 que el pósito vendiese el grano a precio del Almudí. Esta medida se fundamentó en la necesidad de dotar de fondos propios al pósito, destinados tanto a evitar contraer préstamos a corto plazo con un interés de un $4,5 \%$ ó $6 \%{ }^{130}$ como a construir sus propios hornos y eliminar así la presión de los horneros sobre el mercado. Con el precedente de la cédula real que dictó en noviembre de 1801 que el abasto de las panaderías de Madrid se rigiese por el precio del grano en el mercado, el Consejo de Castilla aprobó esta gestión para el pósito de Zaragoza en agosto de 1802 . Pese a esta cesión, los objetivos inmediatos del pósito se vieron retrasados por las serias carestías de grano sufridas en 1802-1805. Así, si bien la Junta de graneros designó en febrero de 1808 una comisión encargada de crear hornos municipales para frenar el fraude de los horneros, el proyecto se calificó de prematuro ante las carencias de dinero ${ }^{131}$.

La ampliación de la actividad del pósito de Zaragoza a fines del siglo XVIII requirió tanto mantener la sujeción del abasto de los horneros en los silos municipales como

129. AMZ, Caja 467, 1781, 9 de julio, 1788, 10 de enero, Caja 469, 1793, 14 de mayo, Caja 471, 1802, 28 de marzo, 5 de junio, 14 de agosto y Caja 473, 1808, 10 de febrero.

130. Como ejemplos, AMZ, Caja 471, 1802, 25 de octubre, 10 de noviembre, 1803, 5 de enero, Caja 472, 1804, 21 de noviembre y Caja 473, 1807, 18 de septiembre.

131. AMZ, Caja 469 y 471 y Act. Mun., 1789, 1802 y 1805. 
requerir la cooperación los principales sectores implicados en el mercado de grano: la nobleza titulada e Iglesia que disponía de notables excedentes procedentes de diezmos y rentas señoriales detraídas al campesino y la burguesía mercantil que controlaba su comercialización ${ }^{132}$. Muestra de su dependencia, el pósito debía pagar en ocasiones al contado a estos grupos sociales o remitir el precio final del grano adquirido a su valor en el Almudí en los meses previos a la siega, cuando alcanzaba su máxima cotización anual ${ }^{133}$. La creciente renuncia del pósito de Zaragoza desde 1780 a contener las fluctuaciones del precio del grano que tenían lugar en el Almudí hizo este acomodo posible al preservar los elevados beneficios de estos poderosos sectores en detrimento de la población. Este entendimiento no se vio obstaculizado por la real cedula que eliminó en España en julio de 1790 la libre comercialización de granos y permitía a las instituciones públicas obligar a los dueños del grano venderlo a precio corriente para el abasto de la población. El intendente de Zaragoza se planteó en 1805 embargar los graneros de quienes revendiesen grano sin ser los propietarios directos de excedentes y rentas generando monopolios y usuras; pero evitando atacar de forma directa a los grandes comerciantes ${ }^{134}$.

Junto a la colaboración de los principales grupos sociales implicados en las transacciones de granos, ante las mayores carestías sufridas en Aragón a fines del siglo XVIII y principios del siglo XIX, el concejo pudo dotarse de mecanismos de regulación del comercio interregional y mercado local ${ }^{135}$. Como ya se había obtenido en 1780 , con los informes favorables de la Real Audiencia, el Consejo de Castilla concedió la prohibición de exportar granos de Aragón por el río Ebro tras las cosechas de 1789, 1793, 1794, 1795, 1802, 1803, 1804 y 1805. Si bien esta veda no frenó su exportación

a Cataluña, como muestra el traslado de grano por arriería desde el partido de Huesca al mercado de Lérida denunciado en 1802 y 1804, el control del tráfico de mercancías por el río Ebro desestimó ciertas iniciativas de los comerciantes al encarecer el transporte y forzó a muchos municipios catalanes -incluida Barcelona- a solicitar permiso a Zaragoza para extraer grano a través del río Ebro. La Real Audiencia recabó la colaboración de las autoridades locales para favorecer las compras de grano en distintas comarcas aragonesas realizadas por los delegados del pósito de Zaragoza. En aras de asegurar el suministro de la población local, el concejo reguló en los años de carestía las cantidades de pan que podían extraer de la ciudad los forasteros. Pese a estas medidas, el alza de los precios del grano en el período 1789-1808 incentivó en gran medida las prácticas de reventa en la ciudad.

132. AMZ, Cajas 467, 468, 469, 470, 471 y 472.

133. Como ejemplos, AMZ, Caja 464, 1794, 29 de diciembre, Caja 471, 1800, 22 de noviembre, Caja 472, 1805, 26 de junio, 16 de octubre, Caja 473, 1808, 26 de enero.

134. AMZ, Caja 472, 1805, 4 de octubre.

135. AHN, Consejos, legajo 6869, numero 27 y AMZ, Caja 468, 469, 470, 471 y 472. Como ya sucedía con anterioridad, las prohibiciones de extraer grano de Aragón dictadas en este período excluían de forma taxativa las zonas de Teruel y Albarracín, cuya economía dependía de la exportación de grano a Valencia. 


\section{CONCLUSIONES}

Como conclusiones, la regulación municipal sobre el mercado de grano aragonés experimentó una clara evolución durante la Edad Moderna. La consolidación de los pósitos durante el siglo XVI fue posible no sólo gracias al auge municipal sino al fuerte consenso social desatado en torno al mercado de grano y al interés de las elites locales en apoyar mediante su regulación un sistema de crecimiento económico introvertido. Al intervenir de forma más constante en el mercado, los concejos no sólo mejoraron el abasto de la población, sino que intentaron contener la inflación de precios, potenciar la demanda e incentivar la producción agraria y el comercio dentro del reino para generar una mayor integración voluntaria de amplios sectores sociales en el mercado público. Con estos fines, los pósitos aumentaron sus compras y ventas de grano y asumieron pérdidas para aminorar las alzas de precios en años de escasez. Pese a la contratación de censales para paliar el déficit municipal, el incremento de sus existencias dotó a los pósitos de una gran fragilidad frente a las oscilaciones de precios, cuyas bruscas alteraciones a fines del siglo XVI les acarrearon serias pérdidas e impusieron remodelar la gestión de los pósitos.

La paulatina afirmación de un modelo económico más extrovertido durante el siglo XVII potenció esta reforma de los pósitos al orientar los intereses de las elites locales a la exportación de grano y otras materias primas hacia Cataluña y Valencia en vez de sustentar la demanda interna. Desde principios de la centuria, sin descuidar las más serias carestías, los pósitos introdujeron una gestión más rentable al reducir las existencias de grano en sus silos y gravar más su venta, medidas consagrada en la segunda mitad de la centuria al descender los precios del grano junto con la demanda interna. Facilitada por el cierre de las elites locales en el concejo y la menor participación de los grupos más humildes, la contracción de la política de abastos perjudicó al consumidor y generó una ruptura del consenso social sobre el mercado que se tradujo en protestas, litigios y fraudes que implicaron a gran parte de la población, incluidos los estamentos privilegiados. La pérdida de control sobre el mercado de grano resultante forzó a los concejos a intentar suprimir privilegios privados abusivos y permitir iniciativas particulares en pro de una mayor eficiencia que no salvaron por completo el deterioro del abasto público. Pese a favorecer la fundación de Montes de Piedad dedicados a prestar simiente a labradores, la debilidad financiera concejil y la remisión del problema a vínculos privados limitaron esta actividad pública en beneficio de la capacidad de detracción de los grupos más poderosos, quienes consolidaron un proceso de integración forzada del campesino en el mercado a través de su endeudamiento que se prolongó durante toda la Edad Moderna.

Las líneas esenciales trazadas en el siglo XVII se mantuvieron durante la centuria siguiente al perpetuarse la debilidad financiera municipal y crecer la extroversión de la economía aragonesa, cada vez más orientada a la exportación de materias primas. Mermadas sus existencias por las requisas e impuestos durante la Guerra de Sucesión y condicionada su gestión por la injerencia de Juntas de censalistas, los pósitos mantuvieron una intervención moderada en el mercado que planteó problemas de abasto 
al crecer la demanda interna y externa de grano a mediados del siglo XVIII. La mayor intervención estatal, orientada durante la centuria a moderar los beneficios de los pósitos para favorecer el abasto, se recrudeció en este período al intentar favorecer el libre tránsito de grano hasta culminar con la proclamación del decreto de libre comercio en 1765. Como demuestra el caso de Zaragoza, su aplicación redujo la actividad de los pósitos sin gestarse un abasto satisfactorio al combinarse criterios inadecuados de intervención en el mercado con la misma preservación del monopolio sobre la venta de pan por los concejos para tratar de salvar su debilidad financiera. Al devolver el Estado a las elites locales desde 1790 una mayor capacidad de regular el mercado de grano ante la presencia de serias carestías, los pósitos extremaron su endémica dependencia respecto a grandes comerciantes y nobles en perjuicio del libre comercio y en beneficio de la especulación en los mercados. Los intentos realizados en Zaragoza de adoptar criterios más flexibles de gestión a fines del siglo XVIII resultaron tardíos e insuficientes para mejorar el abasto, motivo que facilitó el derrumbe del sistema al emerger las revoluciones liberales. 